\title{
EL EMPADRONAMIENTO MUNICIPAL EN ESPAÑA: EVOLUCIÓN LEGISLATIVA Y TIPOLOGÍA DOCUMENTAL ${ }^{1}$
}

\author{
THE MUNICIPAL CENSUS \\ IN SPAIN: LEGISLATIVE CHANGES \\ AND TYPOLOGY OF DOCUMENTS
}

\author{
MARIANO GARCÍA RUIPÉREZ \\ Archivo Municipal de Toledo
}

\begin{abstract}
Resumen: En este artículo se analiza el origen y características de las fuentes documentales conservadas en los archivos municipales para el estudio demográfico de la población española, con la ayuda de la normativa aprobada para el empadronamiento de los habitantes desde el siglo XVIII a la actualidad. En el texto se da cuenta del origen de los padrones municipales de habitantes y de los cambios que afectan a esta serie documental tanto en su periodicidad (anual o quinquenal) como en su contenido y tramitación.

Palabras clave: España, Historia, Edad Contemporánea, Ayuntamientos, Administración Local, Legislación Local, Población, Demografía, Archivos municipales, Documentos, Padrones municipales, Censos de habitantes, Tipología documental.
\end{abstract}

Abstract: This paper focuses on the origin and main characteristics of the documentary sources preserved in municipal archives suitable for demographic studies on Spanish population, being of great help every legislation approved, from eighteenth century to present day, in order to enumerate the inhabitants of a specific territory. The article also features the origin of the municipal population census and the changes that affected the periodicity (annual or five-year), content and processing of its series of records.

Keywords: Spain, History, Councils, Local Government, Local Legislation, Population, Demography, Municipal Archives, Documents, Population Census, Typology of documents.

\footnotetext{
${ }^{1}$ El presente trabajo forma parte del proyecto de investigación: "Familia, curso de vida y reproducción social en la España centro-meridional, 1700-1860”, referencia HAR2010-21325-C05-03, del que es Investigador Principal Francisco García González y ha sido posible gracias a la financiación concedida por el Ministerio de Ciencia e Innovación.
} 


\section{ORÍGENES DE LOS PADRONES DE HABITANTES}

La realización de recuentos poblacionales de manera periódica y con fines a priori meramente estadísticos no se produce en España hasta el establecimiento del régimen liberal decimonónico. Obviamente durante el Antiguo Régimen se formalizaron vecindarios, matrículas, listas, estados, relaciones, alistamientos, censos, padrones o catastros en muchos municipios que permiten trazar la evolución demográfica en los distintos reinos peninsulares, pero que salvo consabidas excepciones como el censo de Aranda o el censo de Floridablanca, ambos en el siglo XVIII y realizados por la Corona, respondieron casi siempre a necesidades hacendísticas o militares. También los hubo que fueron elaborados por cuestiones relacionadas con la sanidad y los abastos.

En los archivos municipales españoles suelen conservarse esos padrones, con distintas denominaciones, con diferentes finalidades y con variados contenidos, redactados desde la Baja Edad Media. Los hay que bajo el nombre de "alardes", ya a finales de la Edad Media, recogen sólo a los vecinos que disponían de armas y caba$11 \mathrm{~s}^{2}$.

Durante el Antiguo Régimen, la mayoría de los padrones conservados en los ayuntamientos tienen un claro origen fiscal. En la Corona de Castilla fue general la realización de padrones de pecheros para el repartimiento o derrama entre ellos de los distintos tributos, como reflejan varios cuadernos de Cortes y queda recogido en distintas leyes publicadas en la Novísima Recopilación ${ }^{3}$. Así, Juan II, en el año 1451, encargó a los escribanos municipales que realizaran los padrones de monedas y los asentaran en "el libro del Concejo". Esta situación se mantuvo en los reinados posteriores como queda de manifiesto en otras leyes recogidas en esa misma obra. El cobro de los servicios de "moneda forera y milicias", de origen medieval, implicó la realización en muchas poblaciones, y de manera periódica, de padrones y vecindarios generales, con distinción de estados (pecheros, hidalgos, exentos y eclesiásticos) hasta su supresión en el año 1724. Y lo mismo ocurría con otros tributos.

\footnotetext{
${ }^{2}$ De los registros elaborados por los ayuntamientos, desde la Edad Media hasta el siglo XIX, para conocer a los propietarios de caballos en su localidad trata la obra El control del ganado equino en España en la Edad Moderna: El Libro registro de caballos de Toledo del año 1535, Toledo, 2008.

${ }^{3}$ Novísima Recopilación de las leyes de España: dividida en XII libros: en que se reforma la Recopilación publicada por el Señor Don Felipe II... y se incorporan las pragmáticas, cedulas, decretos, ordenes... expedidos hasta... 1804..., Madrid, 1805-1807, Libro VI, Título XXII, Leyes I-III, V, VIIX, pp. 261-263,
} 


\section{MARIANO GARCÍA RUIPÉREZ \\ EL EMPADRONAMIENTO MUNICIPAL EN ESPAÑA}

Otro ejemplo muy claro en este sentido nos lo ofrece el catastro del marqués de la Ensenada, pues no olvidemos que la información contenida en él estaba motivada por la creación de la "Única Contribución" para las poblaciones castellanas, es decir tenía una finalidad fiscal. Este Catastro, redactado a mediados del siglo XVIII, es el ejemplo más significativo de la utilidad de los encabezamientos y repartimientos de contribuciones para los estudios demográficos, al menos en el ámbito castellano.

El origen de los padrones motivados por prestaciones militares al Estado está menos estudiado. Pero de ellos se hace mención en las ordenanzas del Ejército, pues servían de base para realizar los distintos alistamientos ${ }^{4}$. Esos padrones de vecinos, al menos según el párrafo $1^{\circ}$ del capítulo $8^{\circ}$ de la Real Ordenanza de reemplazos de 27 de octubre de 1800, debían ser realizados por los ayuntamientos cada diez años ${ }^{5}$. El periodo convulso de la Guerra de la Independencia motivó la elaboración de nuevos padrones de vecinos acortando los plazos establecidos en esa Ordenanza.

La realización de padrones con una finalidad inespecífica no fue nada habitual durante el Antiguo Régimen, aunque se pueden encontrar algunos ejemplos. Uno de ellos pudo venir motivado por la aprobación, el 10 de noviembre de 1736, de una Real Orden de la Chancillería de Valladolid por la que se obligaba a realizar de nuevo un padrón general en los lugares de su jurisdicción, con distinción de estados, de todos los vecinos, pero "sin que contenga repartimiento de contribución que no deba hacerse" . Esta disposición, cuyo alcance desconocemos, sería un precedente claro, aunque limitado, de una fuente documental demográfica en el Antiguo Régimen sin una finalidad hacendística o militar expresa. De todas formas sólo recogería el nombre y estado de los vecinos, cabezas de familia, no de la totalidad de sus habitantes.

\footnotetext{
${ }^{4}$ Pocas veces se han conservado en los archivos municipales estos padrones. Más habitual es encontrar "padrones de alistamiento" en los que se incluye sólo a los varones solteros comprendidos en un determinado grupo de edad, susceptibles de ser incorporados en el correspondiente reemplazo. Véase por ejemplo el contenido de la Real Ordenanza de 27 de octubre de 1800, recogida como Ley XIV, Título VI, Libro VI, en la Novísima Recopilación..., pp. 82-85.

${ }^{5}$ Así se recordó, por ejemplo, en la provincia de Toledo, en una Circular impresa de su Intendencia fechada el día 19 de agosto de 1819.

${ }^{6}$ Un auto de la Sala de esa Chancillería de 20 de septiembre de 1798 ordenó la reimpresión de esa Real Orden y su remisión a las localidades incluidas en su distrito "a causa del descuido y negligencia que muchas de las justicias de los pueblos [tienen]... en la observancia de la formación de Padrones".
} 


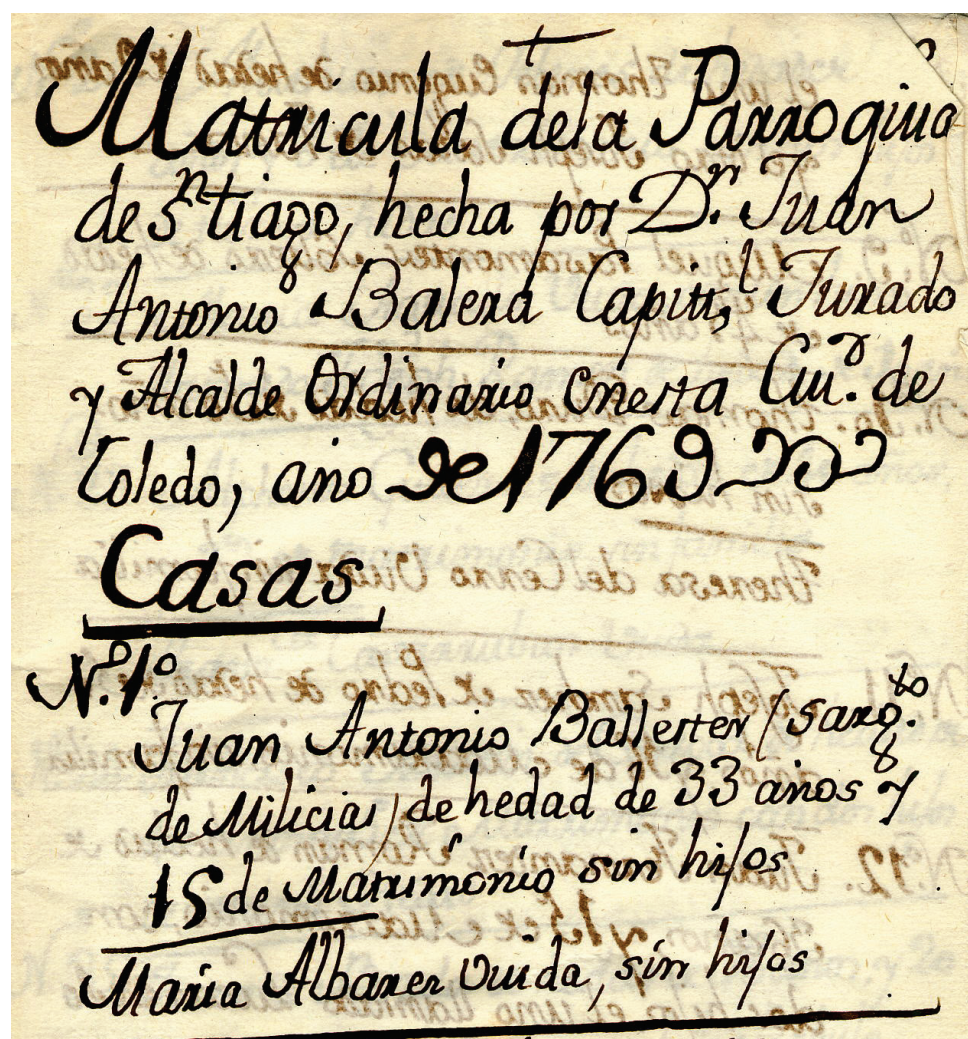

No2. Iph Rodxua dehedad de 13 anos o

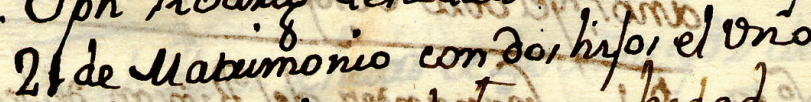

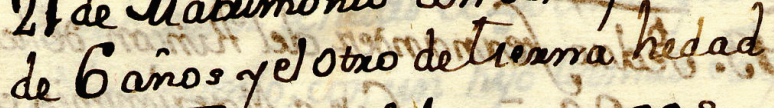
Manuel Sexwano dehedad as S5a, rido N3. Manuel Gomer de hedad r 18 y 2 de Mataimonio, sin hipos

v. A. Dptoval dela Cuenda déhedad de $35^{\circ}$ a. y 12 de Marímonio, con 3 hilo el vro de 9 años y Los dos de corte hedad r.'S Thelipe Gomraler dehedad r 14 io $y$ 3re Manumonio con 3 hilos el vrro lama

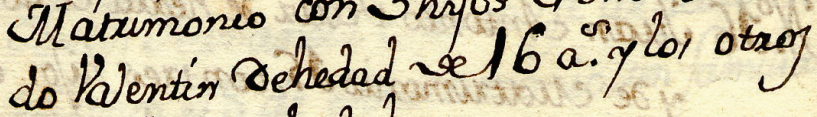
dos de Tiêna hedad.

Figura 1. Hoja primera de la matrícula de habitantes de la parroquia de Santiago de Toledo del año 1769. 
La documentación municipal, y por ende la estatal, no puede sustituir a los libros sacramentales llevados en las parroquias españolas desde su establecimiento en el Concilio de Trento, aunque en algunas diócesis ya se asentaban en registros los bautismos, casamientos y entierros desde principios del siglo XVI. La administración central recordó en repetidas disposiciones ${ }^{7}$ la importancia de su formalización y conservación en las respectivas iglesias parroquiales. Los curas párrocos fueron obligados a cumplimentar distintos estados numéricos con la información extraída de esos libros sacramentales, que debían remitir todos los meses a sus respectivos obispos y arzobispos para que ellos a su vez los hicieran llegar a los organismos estatales ${ }^{8}$. Los modelos de esos formularios fueron circulados con la Real Orden de 15 de octubre de $1801^{9}$.

Esos estados que reflejaban la evolución demográfica con una finalidad a priori exclusivamente estadística no se conservan en los archivos municipales al no participar las autoridades locales en su tramitación. Sí intervendrán, ya en 1797, en la cumplimentación del conocido como Censo de Godoy, circulado por Real Orden de 28 de agosto de ese año, con la intención de conocer el verdadero estado de la población española y averiguar las causas que impedían el desarrollo de la agricultura, industria y comercio.

Este Interrogatorio, circulado en 1797, podemos considerarlo, tal vez, como la primera medida que abarcando todo el territorio español pretendió conocer su situación demográfica sin que detrás de la obtención de esa información hubiera expresamente una finalidad hacendística o militar. Lo cierto es que cinco años después, por Real Orden de 14 de octubre de 1802, se circuló un nuevo interrogatorio que respondía a los deseos del monarca de "que cada cinco años se renueven los estados de población del Reyno" ". En un total de noventa preguntas, que debían contestar las autoridades locales, se debía dar respuesta a cuántos vecinos tenía el pueblo (pregunta 5), al número concreto de solteros, casados o viudos, distinguidos por sexo y por once grupos de edad (pregunta 7), a cuántos de ellos eran jornaleros (pregunta 44) o mercaderes (pregunta 54), por poner algunos ejemplo de su contenido ${ }^{11}$.

\footnotetext{
${ }^{7}$ Ejemplo sería la Real Orden de 21 de marzo de 1749 recogida en extracto en la Novísima Recopilación ..., Libro VII, Título XXII, Ley X, nota 10.

${ }^{8}$ Real Orden de 8 de mayo de 1801, inserta en Circular del Consejo de 23 de mayo de ese año, y publicada íntegra como Ley X, Título XXII, Libro VII de la Novísima Recopilación..., pp. 504-506.

${ }^{9}$ Ídem..., nota 11.

${ }^{10}$ Este documento se denomina "Interrogatorio a que deben contestar todos los pueblos de España, para que el Departamento del Fomento General del Reyno y Balanza de Comercio pueda presentar el Censo de Población que le ha encargado S.M."

${ }^{11}$ Un ejemplar impreso de este Interrogatorio se conserva en el Archivo Municipal de Toledo (AMT), caja 744.
} 


\section{MARIANO GARCÍA RUIPÉREZ \\ EL EMPADRONAMIENTO MUNICIPAL EN ESPAÑA}

Resumamos. Hasta el siglo XIX no suele haber dos padrones con una estructura informativa similar e incluso hay variaciones entre los distintos asientos registrados en un mismo listado. Su clasificación archivística depende de su finalidad pero ésta no siempre es fácil de conocer si el documento ha perdido la relación con su contexto histórico. La mención de la edad de los vecinos, incluyendo todos los que tenían más de 16 años, y la no aparición de ninguna mujer, ni siquiera de las viudas, indica que el padrón tuvo una finalidad militar (quintas y milicias). Pero si se recoge algún bien concreto, o una determinada cantidad, de todos los vecinos (incluidas las mujeres cabezas de familia) es muy posible que ese listado fuera realizado para el cobro de un determinado tributo.

Durante el Antiguo Régimen los nombres de los vecinos recogidos en esos listados suelen estar ordenados por parroquias y dentro de éstas por un número dado a cada casa (casa hita) y que varía en cada recuento. La numeración de los inmuebles, reflejada en azulejos incrustados en las fachadas, no fue habitual en muchas localidades españolas hasta el siglo XIX, e incluso después. Lo mismo podemos decir de una concreta denominación de las calles.

Hay que esperar, también, a las primeras décadas de ese siglo para encontrar padrones generales, realizados con una finalidad no específica, en los que se incluya el nombre y apellidos de todos los habitantes de una localidad (no sólo de los cabezas de familia), el domicilio completo, la profesión, la edad, el lugar de nacimiento, y su parentesco dentro de la unidad familiar ${ }^{12}$.

En todo caso una de las características básicas de los padrones conservados anteriores al siglo XIX es que recogen datos de los vecinos (cabezas de familia), no de los habitantes, por lo que en ellos sólo suelen aparecer los cabezas de familia (incluidas las viudas), es decir en torno a una quinta parte de la población ${ }^{13}$.

La cumplimentación de los estados periódicos de nacidos, casados y muertos comenzó a ser una obligación de las autoridades locales, con la aprobación del Decreto de 23 de junio de 1813, que ponía en vigor la Instrucción para el gobierno económico-político de las provincias. En concreto en su art 2 establecía que "los ayuntamientos enviarán al Jefe Político de la Provincia cada tres meses una nota de

${ }^{12}$ Un precedente de estos padrones es el elaborado en cumplimiento de la Real Cédula e Instrucción de 20 de julio de 1791 sobre permanencia de extranjeros en el Reino, publicada en la Gaceta de Madrid de 13 de septiembre de 1791. En ese padrón se recoge el lugar de nacimiento de todos los inscritos.

${ }^{13}$ Las declaraciones individuales realizadas por los cabezas de familia y presentadas para el cobro de la Única Contribución (Catastro del Marqués de la Ensenada) sí permiten reconstruir las unidades familiares, al reflejar el nombre, edad y condición de todas las personas que vivían bajo su cuidado. Pero esto no es nada habitual. 


\section{MARIANO GARCÍA RUIPÉREZ \\ EL EMPADRONAMIENTO MUNICIPAL EN ESPAÑA}

los nacidos, casados y muertos en el pueblo, extendida por el cura o curas párrocos, con especificación de sexos y edades, de cuya nota conservará el Ayuntamiento un registro". En esa nota se daría cuenta además de las enfermedades por las que hubieran fallecido los vecinos de la localidad.

Pocos días después, en concreto el $1^{\circ}$ de julio de 1813, al aprobarse la Instrucción dirigida a los Jefes Políticos de las Provincias para el establecimiento y organización de la correspondencia de oficio que habían de seguir con la Secretaría de la Gobernación de la Península e Islas adyacentes, se obligaba a los ayuntamientos a elaborar, en los primeros días de cada mes, una relación o tabla de los muertos, nacidos y matrimonios habidos en el mes anterior, según un modelo impreso contenido en esa disposición.

Por lo tanto, el gobierno gaditano estableció la cumplimentación de estados mensuales y trimestrales con una finalidad estadístico-sanitaria. E incluso encargó a las Diputaciones provinciales que elaboraran anualmente "el censo y la estadística de su provincia" valiéndose de la información aportada por los ayuntamientos ${ }^{14}$. Pero en la normativa aprobada esos convulsos años no hay referencias a la redacción de padrones de habitantes. De todas formas una Real Cédula de 30 de julio de 1814 supuso la desaparición de los ayuntamientos nacidos de las Cortes de Cádiz, volviendo por lo tanto a la situación existente en 1808.

Los interrogatorios, los estados numéricos (mensuales, trimestrales o anuales) y los padrones de vecinos, bien para servir de base a la formación del alistamiento de quintos o bien para el repartimiento de cualquier contribución, constituyen las fuentes documentales básicas conservadas en los ayuntamientos para conocer la población en las primeras décadas del siglo XIX.

\section{LOS PADRONES DE HABITANTES ANUALES (1823-1869)}

La realización de padrones de población con una finalidad no específica aparece contemplada de una manera clara, y por primera vez en la legislación general española sobre régimen local, en el Decreto de 3 de febrero de $\mathbf{1 8 2 3}$ por el que se aprobaba la Instrucción para el gobierno económico-político de las provincias ${ }^{15}$. En

\footnotetext{
${ }^{14}$ Decreto de 23 de junio de 1813 aprobando la Instrucción para el gobierno económico-político de las provincias, art. XIII del capítulo II, y art. XXXI del capítulo III. Incluido en la obra de T. R. FERNÁNDEZ y J. A. SANTAMARÍA, Legislación administrativa española del siglo XIX, Madrid, 1977, pp. 698 y 701.

${ }_{15}$ Así lo entiende también J. A. SUERO SALAMANCA en su "Estudio sobre el padrón municipal de habitantes”, Actualidad Administrativa, 15 (abril de 1999), pp. 3-19. Véase el artículo de Mª S.
} 
él, además de la obligación de colaborar con las diputaciones para la formación de diferentes estadísticas, se encarga a los ayuntamientos de la formación del censo de población ( $\operatorname{art}^{\circ} 5$ ), siguiendo las indicaciones del gobierno central. A ello añade, en su $\operatorname{art}^{\circ} 6$, que todos los años debían elaborar en el mes de enero "el padrón general para el gobierno y administración de su respectivo pueblo, comprendiendo en él los particulares que sean necesarios, para que sirva a los objetos de policía, de seguridad, y orden de repartimiento de contribuciones y cargas, y de los alistamientos para el Ejército permanente, y para las Milicias nacionales activa y local".

Con este Decreto nace también el Registro Civil, tal y como hoy lo entendemos, con el claro precedente del contenido del $\operatorname{art}^{\mathrm{o}} 2$ del Decreto de 23 de junio de 1813 ya comentado. Así por el $\operatorname{art}^{\circ} 7$ del Decreto de 3 de febrero de 1823 se establece que "habrá en la Secretaría de cada Ayuntamiento un registro civil de los nacidos, casados y muertos en el pueblo y su término, llevándolo con toda formalidad, según se prevenga en el Código Civil, y teniéndolo en la debida custodia”. Y por el $\operatorname{art}^{\circ} 8$ se mantenía la necesidad de cumplimentar los estados trimestrales de nacidos, casados y muertos ${ }^{16}$.

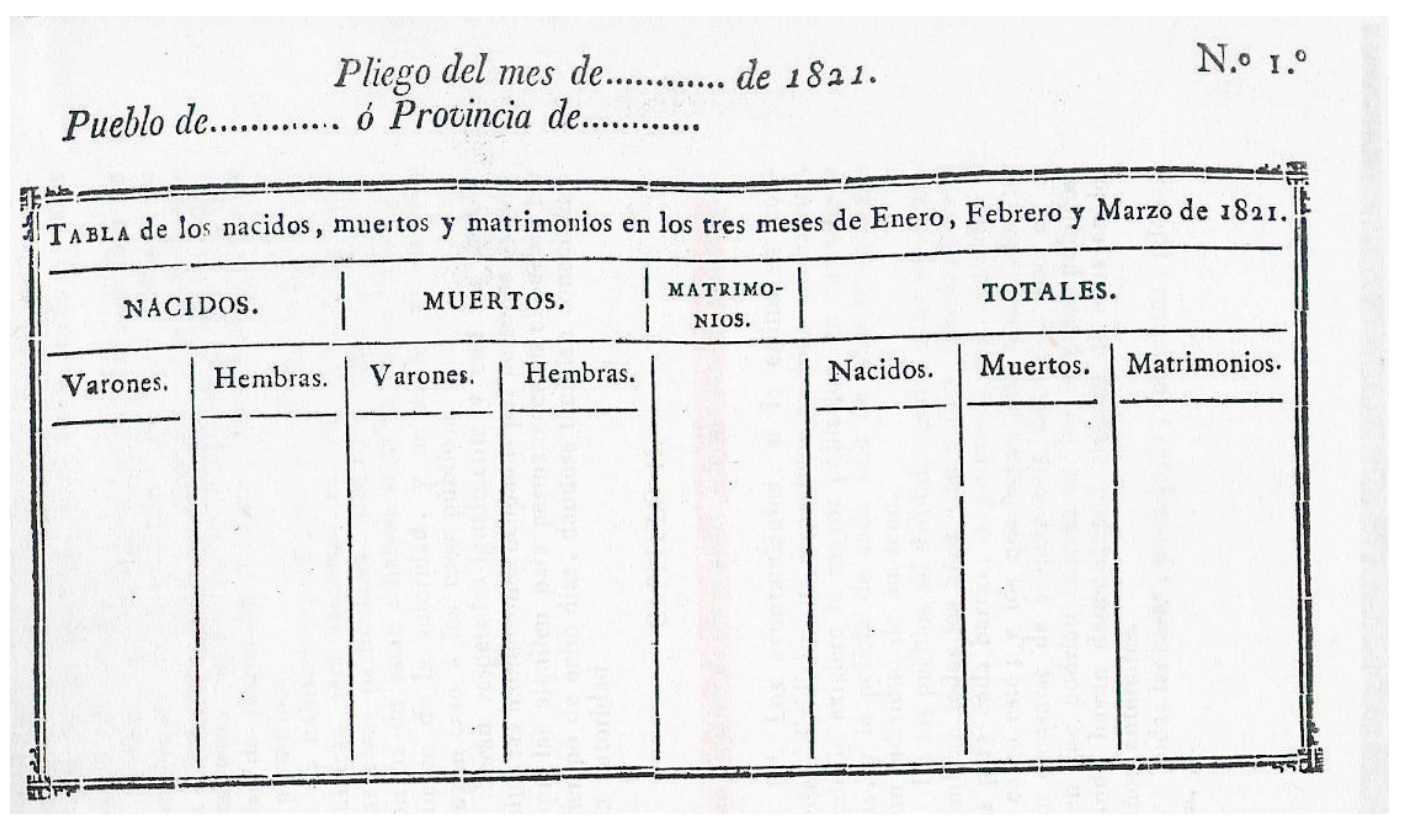

Figura 2. Modelo del estado trimestral de nacidos, casados y muertos establecido en 1821.

GARCÍA PÉREZ, "El padrón municipal de habitantes: origen, evolución y significado", Hispania Nova. Revista de Historia Contemporánea, 7 (2007).

${ }^{16}$ De todas formas la realización de estos estados trimestrales ya había sido recordada en la Instrucción provisional que regulaba la correspondencia de los pueblos con los Jefes Políticos, aprobada por Real Orden de 1 de febrero de 1821 , en su regla $5^{a}$, párrafo $7^{\circ}$. Con la Instrucción se circuló el 


\section{MARIANO GARCÍA RUIPÉREZ \\ EL EMPADRONAMIENTO MUNICIPAL EN ESPAÑA}

Los padrones de población hasta entonces habían respondido básicamente a necesidades militares y hacendísticas, y en ocasiones sanitarias. En el siglo XIX se añade a ellas la policial o de seguridad pública, motivada muy posiblemente por las guerras carlistas y por la inestabilidad socio-política imperante en esos años. En la normativa que establece estos padrones se encuentra el origen actual de estos documentos de control de la población. Y la primera norma que hace referencia a ellos apareció durante el Trienio Liberal. En concreto, por Decreto de 6 de diciembre de 1822, se aprobó el primer Reglamento provisional de Policía que incluía un capítulo relativo a "De la división de los pueblos y formación de padrones". En él se contemplaba no sólo la obligación que tenían los ayuntamientos de proceder a la numeración exterior de las casas y a la colocación de rótulos con la expresión del nombre de las calles, sino también a la formación todos los años de "un padrón general, en que se anotará cada uno de los vecinos con las personas de su familia, criados y dependientes que habitan dentro de su casa o accesorias a ella, expresando en el asiento sus nombres y apellidos, patria, edad, estado, clase, oficio o destino y tiempo de su residencia en el pueblo ( $\left.\operatorname{art}^{\circ} 11\right)$. En este padrón se debían incluir todos los habitantes, incluyendo los que residían extramuros, o en los conventos, presidios, etc.

En esta misma norma se contempla la existencia de los precedentes documentales de la alta, baja o cambio de domicilio en el padrón al establecer, en su $\operatorname{art}^{0} 14$, que los que "mudaren de domicilio o vecindad deberán presentar a la autoridad del pueblo que eligiesen documento que acredite su despedida del anterior".

El Decreto de 3 de febrero de 1823 apenas llegó a entrar en vigor. La reacción absolutista derogó la mayor parte de la normativa aprobada durante el Trienio Liberal. Sin embargo, no ocurrió lo mismo con el Decreto de 6 de diciembre de 1822, cuyo contenido fue ampliado por una Real Orden de 20 de febrero de 1824 que aprobaba el Reglamento de Policía de Madrid y el Reglamento de Policía para las Provincias. Con estas dos disposiciones se difundieron también los modelos de los documentos en ellos contemplados ${ }^{17}$.

modelo del estado denominado como "Tabla de los nacidos, muertos y matrimonios en los tres meses..."

${ }^{17}$ Ya en una normativa anterior, en concreto en una Real Cédula de 13 de febrero de 1824, se dieron reglas para el establecimiento de la Superintendencia general de la Policía del Reino. En su artículo 13 se establece que entre las atribuciones privativas de la Policía se encuentra: "1a Formar padrones exactos del vecindario de los pueblos del Reino, expresando la edad, sexo, estado, profesión y naturaleza de todos los individuos, con arreglo a los modelos impresos que a este fin formará y circulará el Superintendente general". 


\section{MARIANO GARCÍA RUIPÉREZ \\ EL EMPADRONAMIENTO MUNICIPAL EN ESPAÑA}

La regulación de la formación del "padrón general del vecindario" es muy extensa en ambos reglamentos. El de Madrid dedica a este apartado los artículos 61 a 72. Por el artículo 71 del de Provincias se determinó que las matrículas de vecinos se debían formar en todos los pueblos del Reino, tal y como se establecía para Madrid. Es decir, en el padrón estarían inscritos todos los vecinos, cualquiera que fuera su clase y condición. Y para su realización se debía utilizar un modelo impreso, que por entonces se circuló, diferente para los vecinos y para los forasteros.

Ese padrón sería rectificado cada año, durante los primeros quince días de enero, y con él los intendentes formarían y rectificarían "el padrón del vecindario de sus provincias".

En esta disposición del año 1824 ya están contempladas las hojas familiares, denominadas "hojas de matrícula" 18 . Se debía cumplimentar una por cada casa o unidad familiar, que debía firmar el respectivo cabeza de familia. Los forasteros rellenaban también sus hojas de matrícula con arreglo a un modelo distinto. La información contenida en esas hojas se asentaba, después, en registros de formato librario, denominados por la norma como "padrón general en libros", uno para los vecinos de la localidad y otro para los forasteros. Para su utilización se requería la formación de índices alfabéticos por apellidos. Los cambios de domicilio dentro de una misma localidad debían plasmarse en otro formulario.

Como los padrones debían rectificarse todos los años esto daba lugar a que el proceso se repitiera con esa periodicidad.

De gran importancia será, pues, que con estos reglamentos se aprueben los modelos impresos tanto de las hojas de matrícula como del padrón general en libros y de los índices. Estos formularios serían utilizados a partir de entonces en todos los municipios españoles, y en su aplicación está el origen de la serie documental de los padrones municipales de habitantes producidos en lo siglos XIX y XX, que nace vinculada a una finalidad policial y de orden público, no meramente estadística.

La muerte de Fernando VII y la desaparición subsiguiente de las instituciones del Antiguo Régimen, tras el triunfo de la revolución liberal burguesa, significó la vuelta al régimen local aprobado en las Cortes de Cádiz, y concretado en la aprobación del Real Decreto de 23 de julio de 1835 para el arreglo provisional de los Ayuntamientos del Reino. En esta disposición no hay referencias expresas a los pa-

\footnotetext{
${ }^{18}$ Para añadir confusionismo, en el modelo impreso las "hojas de matrícula" van encabezadas con la denominación de "padrón general", o "padrón de forasteros". Por el contrario el modelo citado en la normativa como "padrón general en libros" no está encabezado en el formulario por la palabra "padrón".
} 


\section{MARIANO GARCÍA RUIPÉREZ \\ EL EMPADRONAMIENTO MUNICIPAL EN ESPAÑA}

drones de habitantes, ni en su título $\mathrm{V}$ referido a las facultades y obligaciones de los Alcaldes, ni en su título VII, que recoge las de los Ayuntamientos. Eso sí, a los primeros les competía ( $\operatorname{art}^{\mathrm{o}} 36,8^{\mathrm{a}}$ ) "anotar en diferentes libros los nacidos, casados y muertos en su respectivo territorio, a cuyo fin le pasarán los vecinos el correspondiente aviso, dentro de 48 horas..." bajo pena de multa.

Una de las disposiciones más interesantes aprobadas durante la primera mitad del siglo XIX, en relación con el control de la población, fue el Real Decreto de 29 de junio de 1837 mandando formar el Censo de la Población de España ${ }^{19}$. Con él se publicó una prolija Instrucción general para formar los estados o censos de las provincias a cargo de las diputaciones provinciales, tal y como se contemplaba en la Ley de 3 de febrero de 1823. Para su realización era fundamental llevar a cabo el empadronamiento general en todos los municipios españoles, aunque, por el artículo $3^{\circ} \mathrm{de}$ ese Decreto, la Reina Gobernadora se reservaba la designación de la fecha concreta de su inicio. La guerra carlista y el triunfo de los liberales moderados en las elecciones de 24 de septiembre de 1837 impidieron posiblemente la realización de este primer censo general. Aún así, lo llamativo de esta norma es regular por extenso todo el proceso de empadronamiento y difundir, de nuevo, modelos o plantillas de los distintos documentos requeridos. Las "hojas de matrícula" aparecen en ella denominadas como "relaciones domiciliarias de los vecinos particulares".

El $1^{\circ}$ de diciembre de 1837, el Ministerio de la Gobernación aprobó una interesante circular estableciendo reglas para reunir datos numéricos relativos a los nacidos, casados y muertos de cada año ${ }^{20}$. En ella aparecían los modelos oficiales a los que debían adecuarse los libros registros de bautismos, casamientos y defunciones que se llevaban en todas las parroquias, hospicios y otros establecimientos de beneficencia. Además encargaba a los párrocos y superiores de las casas de beneficencia que enviaran a los ayuntamientos los "estados numéricos por trimestres", desde el $1^{\circ}$ de enero de 1838 , con expresión de los nacidos, casados y muertos que hubiera habido en su feligresía o establecimiento en los últimos tres meses. Esos estados, cuyos formularios acompañaban a la circular, debían ser remitidos a los ayuntamientos, durante el mes siguiente al de la conclusión del trimestre ( $\operatorname{art}^{\mathrm{o}} 3$ ). La información contenida en todos ellos sería recopilada por cada ayuntamiento, refle-

\footnotetext{
${ }^{19}$ Colección de las leyes, decretos y declaraciones de las Cortes y de los reales decretos... desde $1^{\circ}$ de enero hasta fin de junio de 1837, Tomo XXII, Madrid, 1837, pp. 390-425.

${ }^{20}$ Colección de las leyes, decretos... desde $1^{\circ}$ de julio hasta fin de diciembre de 1837, Tomo XXIII, Madrid, 1838, pp. 347-364. En esta disposición se señala que ya se pretendió regular esta materia en la Ley de 3 de febrero de 1823, y en las Reales Órdenes de 19 de febrero y de 14 de marzo de 1836.
} 


\section{MARIANO GARCÍA RUIPÉREZ \\ EL EMPADRONAMIENTO MUNICIPAL EN ESPAÑA}

jándola en otros estados denominados como "resúmenes numéricos", también de periodicidad trimestral, y que debían remitir a las diputaciones provinciales ( $\operatorname{art}^{\mathrm{o}} 6$ ).

De todas formas el sistema recibió un nuevo cambio, de gran trascendencia a nivel municipal, con la aprobación del Decreto de la Regencia provisional del Reino de 24 de enero de 1841. Los progresistas, en el poder tras el paréntesis de 1837-1840 y liderados por Espartero, desarrollaron con esa disposición el artículo 7 de la Ley de 3 de febrero de 1823, relativo al establecimiento del registro civil de nacidos, casados y muertos que en muchos municipios, especialmente en los más pequeños, nunca había sido cumplido. Con esta nueva norma se crea el Registro Civil en todas las localidades que fueran capitales de provincia, cabezas de partido o excedieran de quinientos vecinos, haciéndolo depender de las secretarías de sus ayuntamientos. Los jefes políticos de cada provincia mandarían imprimir los libros necesarios, con arreglo a los modelos que con esa norma se circulaban, y los harían llegar a los ayuntamientos ( $\left.\operatorname{art}^{\mathrm{o}} 2\right)$. Desde el día de su recepción comenzarían a anotarse en ellos en cada población los nacidos, casados y muertos. Los curas párrocos no podrían bautizar ni enterrar a nadie si previamente no habían recibido una papeleta del encargado del registro civil en la que constara haber asentado el nacimiento o fallecimiento en los correspondientes libros ( $\left.\operatorname{art}^{\mathrm{o}} 3\right)$. Y en cuanto a los matrimonios serían los párrocos los que comunicarían los celebrados cada día, antes de que transcurrieran veinticuatro horas de ocurrido el desposorio.

Los libros del Registro Civil pueden contener anotaciones a partir del $1^{\circ}$ de enero de 1841 ya que los párrocos fueron obligados a dar cuenta de los nacidos, casados y muertos desde esa fecha hasta la recepción de esos libros en las secretarías municipales $\left(\operatorname{art}^{\circ} 5^{\circ}\right)$.

Los padrones de población anuales, los libros del Registro Civil, y los estados y resúmenes numéricos, ya comentados, son los documentos municipales que básicamente reflejan la evolución demográfica a partir del año 1841, sin olvidarnos de los padrones elaborados con una finalidad específica (militar ${ }^{21}$ o fiscal), que en teoría sólo afectan a parte de los vecinos de cada localidad, y de los censos electorales.

\footnotetext{
${ }^{21}$ Ejemplos de éstos eran los padrones de vecinos que debían sufrir las cargas de alojamientos y bagajes. Sobre su formación en la provincia de Toledo en 1845 es de interés la circular número 211 del Gobierno Superior Político recogida en el Boletín Oficial de la Provincia de Toledo de 7 de agosto de 1845 .
} 
MARIANO GARCÍA RUIPÉREZ

EL EMPADRONAMIENTO MUNICIPAL EN ESPAÑA

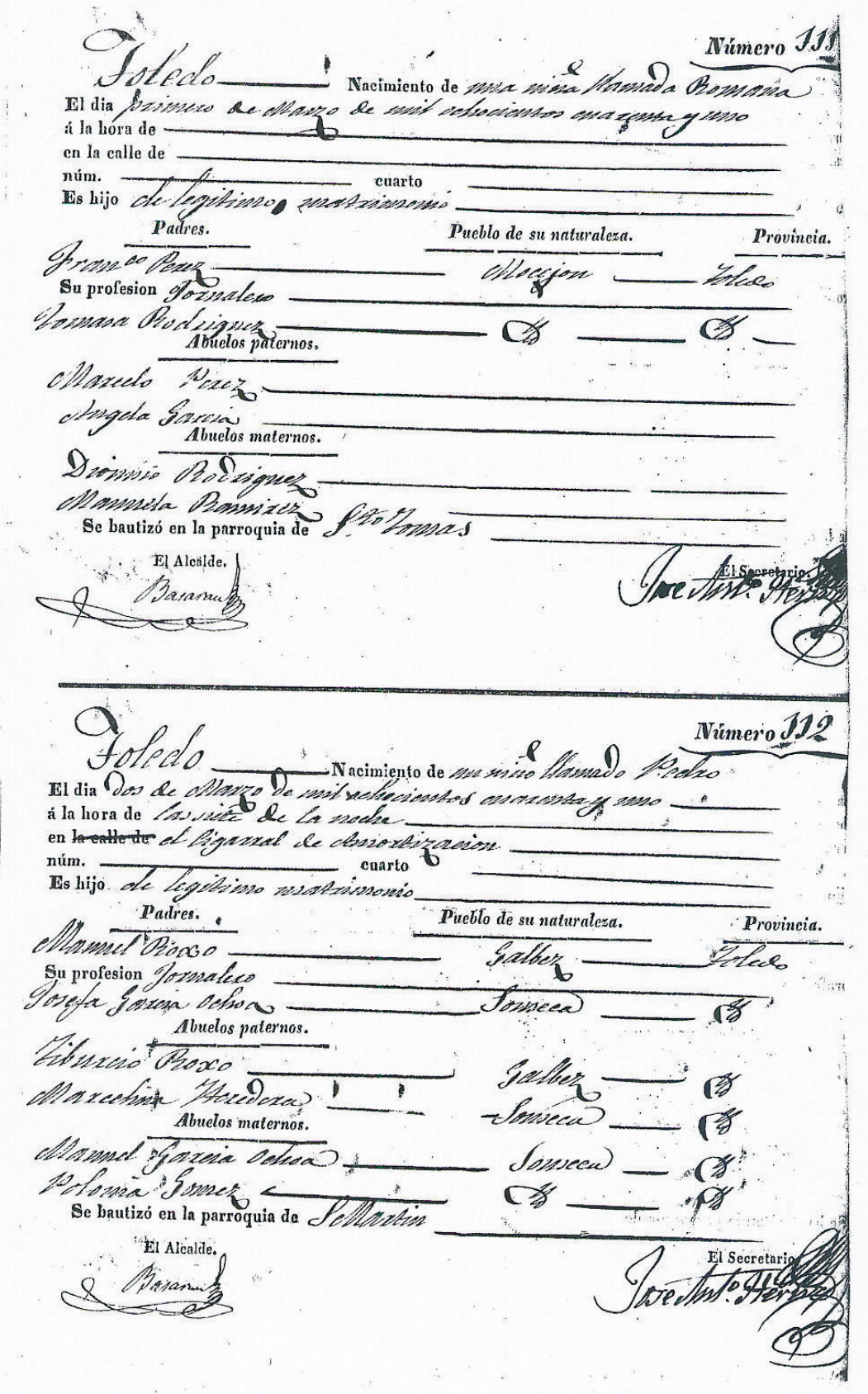

Figura 3. Hoja cumplimentada del Registro Civil de nacidos en Toledo de 1841. 


\section{MARIANO GARCÍA RUIPÉREZ \\ EL EMPADRONAMIENTO MUNICIPAL EN ESPAÑA}

No obstante, una finalidad militar, el repartimiento equitativo entre todas las provincias del reemplazo de soldados del año 1843, motivó el encargo del Gobierno de realizar el "censo verdadero de población", por Real Orden de 17 de septiembre de 1842. Por esta disposición entre el $1^{\text {o }}$ y el 29 de octubre de ese año debía formarse por cada ayuntamiento un padrón exacto y nominal de todos sus vecinos, casa hita. A partir del día 30 de ese mes sería expuesto al público en lugares concurridos. El día 6 de octubre en un pleno del ayuntamiento celebrado a puerta abierta se procedería a su rectificación. Realizada ésta se formaría un extracto del padrón que con el padrón rectificado sería enviado a la respectiva diputación provincial antes del $15 \mathrm{de}$ noviembre. Los modelos del padrón, y de su extracto o resumen, fueron circulados con esa disposición ${ }^{22}$. Estos padrones se formalizaron para dar cumplimiento al capítulo $1^{\circ}$ de la Ley de reemplazos de 2 de noviembre de 1837 y se debían redactar todos los años. La disposición de la información en ellos era distinta de la contemplada en los padrones creados en 1824. En los primeros, los varones eran registrados en tres columnas distintas, según su edad, como se deduce del propio formulario recogido en la Real Orden analizada.

Ninguna referencia a los padrones de habitantes se incluye en la Ley de organización y atribuciones de los ayuntamientos, sancionada en 1840, y publicada el 30 de diciembre de 1843, ni en la Ley de 8 de enero de 1845 de organización y atribuciones de los ayuntamientos. Pero la llegada al poder de los gobiernos moderados introdujo cambios en la normativa sobre el Registro Civil. En concreto por Real Orden de 24 de mayo de 1845 se permitió a los párrocos que pudieran bautizar y enterrar sin haber recibido antes la papeleta del encargado del Registro Civil. Tampoco tenían que comunicar la celebración de un matrimonio en las veinticuatro horas siguientes de haberse producido. A partir de entonces sólo estaban obligados a remitir mensualmente a los ayuntamientos respectivos una nota circunstanciada de los nacidos, muertos y casados en sus feligresías durante ese período ${ }^{23}$. Aún así presuponemos que con esa información se debieron seguir cumplimentado estos registros en los ayuntamientos.

El siguiente cambio normativo que afecta a la documentación relacionada con el empadronamiento se encuentra en un Real Decreto del Ministerio de la Gober-

${ }^{22}$ Boletín Oficial de la Provincia de Toledo de 24 de septiembre de 1842.

${ }^{23}$ Estos cambios y los diferentes modelos fueron recogidos en distintas publicaciones de la época. Véase, por ejemplo, la obra redactada por Tomás GARCÍA LUNA y titulada Boletín oficial recopilado, o Colección completa de todas las leyes, decretos, reales órdenes y reglamentos relativos a la organización y atribuciones de las Municipalidades, Madrid, 1847, capítulo cuarto, pp. 3-14. 


\section{MARIANO GARCÍA RUIPÉREZ \\ EL EMPADRONAMIENTO MUNICIPAL EN ESPAÑA}

nación de 15 de febrero de $\mathbf{1 8 5 4} 4^{24}$. Por él en su art. $1^{\mathrm{o}}$ se establecía la supresión de los pasaportes y demás documentos para transitar por el territorio español a partir del $1^{\circ}$ de mayo de ese año, y la creación en su sustitución de las "cédulas de vecindad". Por la Real Orden de $1^{\circ}$ de abril de $1854^{25}$, se establecieron cuatro clases de cédulas de vecindad. En cada cédula debía figurar el nombre y apellidos paterno y materno del interesado; su estado; profesión, ocupación o empleo; calle, casa y cuarto en que viviere, o la denominación de la vivienda si vivía en una alquería o caserío; y por último, el distrito o provincia a la que pertenecía. El alcalde o comisario las autorizaría con su firma y sello. Y en ellas también se recogería la firma del cabeza de familia, tanto en la suya como en las de las demás personas que estuvieran bajo su dependencia. Para su cumplimentación se utilizaría un modelo impreso. Los alcaldes o comisarios llevarían un registro de cédulas de vecindad con arreglo a un modelo que se publicó con esa Real Orden, en concreto en su art. 13.

La sustitución definitiva de los pasaportes y pases por las cédulas de vecindad, y la desaparición de los refrendos, debió significar un alivio para muchos ayuntamientos y para sus vecinos. Con ellas entramos en los precedentes documentales del actual "Documento Nacional de Identidad" que surgirá ya entrado el siglo $\mathrm{XX}^{26}$.

Tras una década de gobiernos moderados, el alzamiento encabezado por O'Donnell y Espartero, en julio del año 1854, trajo consigo a nivel local la derogación de la normativa de 1845 y su sustitución por la Ley de 3 de febrero de 1823, que estará vigente durante todo el Bienio Progresista. La necesidad de su actualización y modificación implicó la elaboración de una nueva Ley de Ayuntamientos, aprobada el 5 de julio de 1856, que nunca llegó a entrar en vigor, al producirse la dimisión de Espartero ese mismo mes. Su capítulo II del título I, que abarca los artículos 6-24, se refiere a "De los habitantes de los distritos municipales", dedicando especial atención a la adquisición de la condición de vecino, sus derechos y obliga-

\footnotetext{
${ }^{24}$ Gaceta de Madrid de 17 de febrero de 1854.

${ }^{25}$ Gaceta de Madrid de 21 de abril de 1854.

${ }^{26}$ Las cédulas de vecindad, por la Ley de Presupuestos de 8 de junio de 1870, fueron convertidas en un impuesto con el nombre de cédulas de empadronamiento. Por la Ley de Presupuestos de 26 de diciembre de 1872 fueron clasificadas en ordinarias, especiales y gratuitas, y de su posesión sólo estaban exentos los menores de catorce años, las religiosas profesas y los penados durante el tiempo de condena. Los extranjeros con una residencia en España superior a un año estaban obligados a poseer su propia cédula. En un Decreto de 26 de junio de 1874 se denominaron ya como cédulas personales. Setenta años después serían sustituidas por el actual Documento Nacional de Identidad, creado por el Decreto de 2 de marzo de 1944 (Boletín Oficial del Estado de 21 de marzo de 1944).
} 
ciones, y a la rectificación y renovación anual de los padrones de habitantes $\left(\operatorname{art}^{\mathrm{o}}\right.$ $15)^{27}$.

Esta Ley de Ayuntamientos de 1856 es la primera disposición general sobre régimen local que se detiene pormenorizadamente en regular el empadronamiento y el derecho de vecindad. No obstante su aplicación fue nula dado que un Real Decreto de 16 de octubre de ese mismo año restableció en toda su fuerza y vigor la Ley de 8 de enero de 1845 .

La vigencia de la Ley de 3 de febrero de 1823 durante el Bienio Progresista implicó que muchos ayuntamientos tuvieran que seguir redactando los estados de nacidos, casados y muertos, y se les ordenara cumplir los artículos 5 y 6 de esa disposición por la que debían formar el censo de su población, incluyendo un resumen general, de los que algunas diputaciones provinciales circularon modelo ${ }^{28}$. Así fue recordado por una Real Orden del Ministerio de la Gobernación de 17 de diciembre de 1855. Los padrones generales debían elaborarse a lo largo del mes de enero de 1856.

De gran importancia será el Real Decreto de 14 de marzo de $1857^{29}$ que aprueba las bases para la formación del "censo verdadero de todos los habitantes" de España. En su exposición ya se hacía eco de que "los ayuntamientos suelen formar también todos los años sus padrones de vecinos para el servicio de la administración local", pero los datos recogidos en ellos eran inútiles "por irregulares, por poco uniformes y por inexactos". Era preciso que el empadronamiento de toda la población de una localidad se verificase en un mismo y solo día, en todos los pueblos, como se hacía en otros países. Todos los habitantes serían empadronados en la casa en que hubiesen pernoctado el día del empadronamiento.

${ }^{27}$ T. R. FERNÁNDEZ Y J. A. SANTAMARÍA, Legislación administrativa española del siglo $X I X$, pp. 770-771. En el artículo 16 se establece que "Los Ayuntamientos remitirán copia del padrón de vecinos a la Diputación provincial en el mes de Diciembre cada cinco años, y en los años intermedios darán cuenta de las alteraciones que ocurran".

${ }^{28}$ Así lo hizo la Diputación Provincial de Toledo en su circular núm. 17, de 10 de diciembre de 1855, incluida en el Boletín Oficial de la Provincia de Toledo núm. 149 del año 1855. En esta norma el artículo recoge el término "censo", pero en el modelo aparece como "Padrón de la población...". Evidentemente "padrón" y "censo" se utilizan como sinónimos.

${ }^{29}$ Esta norma aparece publicada en la Gaceta de Madrid, núm. 1530, de 14 de marzo de 1857. Hemos manejado el texto reproducido en el Boletín Oficial de la Provincia de Toledo de 17 de marzo de 1857 . 


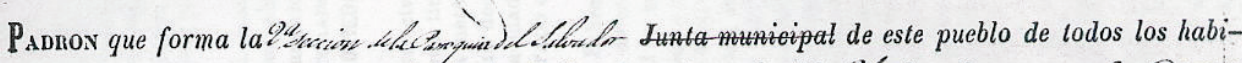
tantes que han pernoctado en el distrito de la misma la noche del If de claysmasman fe Osegun las cédulas de inscripcion que se han repartido y recogido en cumplimiento del Real decrelo de 14 de Marzo de 1857.

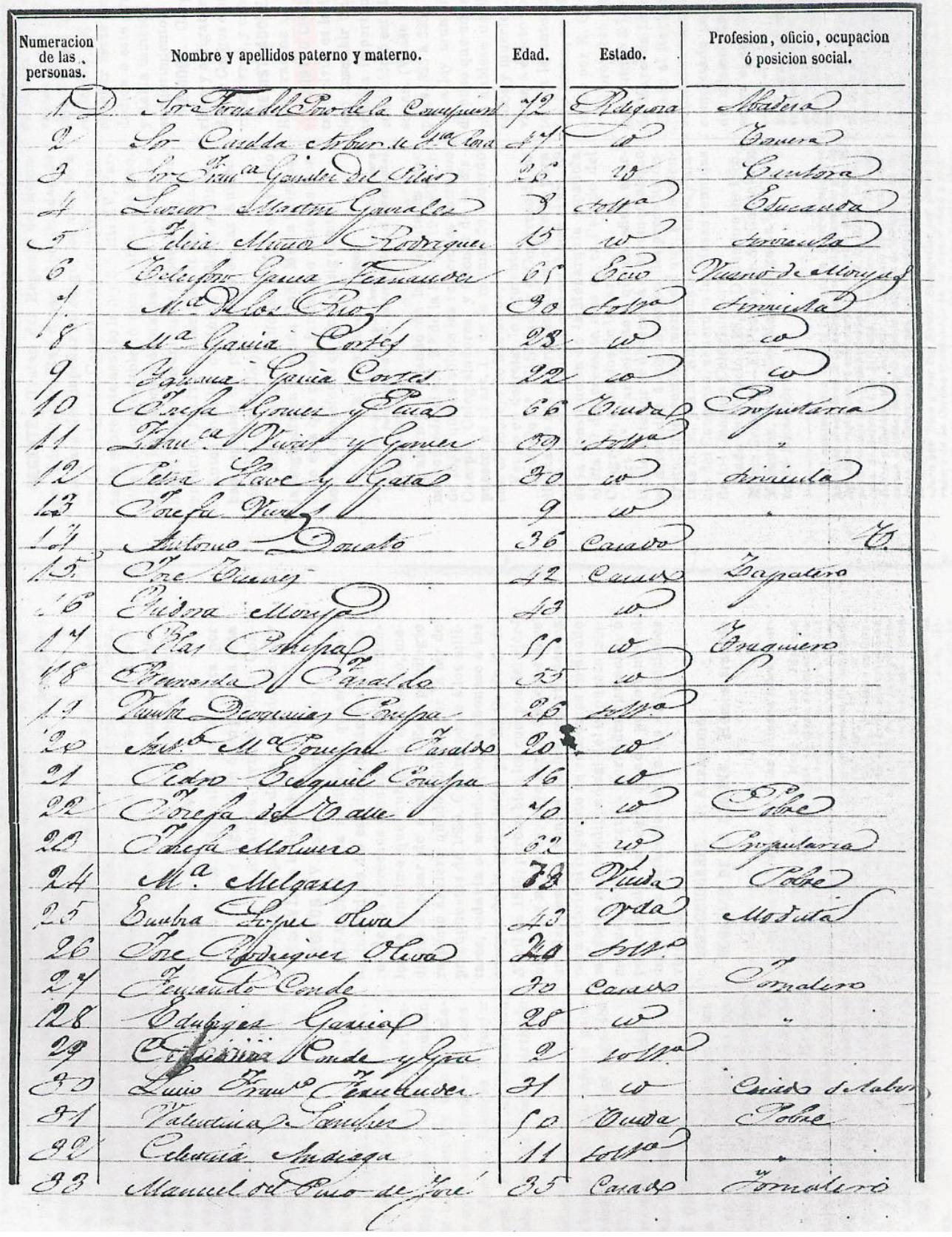

Figura 4. Hoja del padrón realizado con arreglo a la normativa censal de 1857. 


\section{MARIANO GARCÍA RUIPÉREZ \\ EL EMPADRONAMIENTO MUNICIPAL EN ESPAÑA}

Este Real Decreto establece que las "cédulas de empadronamiento" sólo incluirían el nombre, sexo, edad, estado civil y profesión de todos los habitantes de cada localidad, incluidos extranjeros y transeúntes $\left(\operatorname{art}^{\circ} 6\right)$. Con ellas se formarían los "padrones del pueblo" ( $\left.\operatorname{art}^{\circ} 7\right)$, que a su vez servirían de base para los resúmenes de cada partido judicial y con éstos se elaborarían los resúmenes provinciales. Para su ejecución se formarían juntas en cada localidad, presididas por los Alcaldes, de cuya composición trata el artículo 10. Los modelos que debían utilizarse como cédulas de empadronamiento, padrones y resúmenes serían aprobados por el Gobierno y costeados por el Tesoro público $\left(\operatorname{art}^{\circ} 12\right)$.

Un día después, el 15 de marzo de 1857, fue publicada la Instrucción que desarrollaba ese Real Decreto ${ }^{30}$.

El censo fue realizado en toda España con arreglo a la situación de la población el día 21 de mayo de 1857. Los padrones fueron realizados por lo tanto con esa fecha basándose en los datos incluidos en las "cédulas de inscripción”, repartidas y recogidas en cumplimiento del Real Decreto de 14 de marzo de ese año.

Por esos años seguía vigente la Ley de Ayuntamientos de 1845 que, como recordamos, no se refería a los padrones de habitantes. La revolución de septiembre de 1868 motivó que, por Decreto de 21 de octubre, se declarara obligatoria y en vigor la Ley de Ayuntamientos de 5 de julio de 1856. En ella se dividía a los habitantes de cada localidad en residentes y vecinos. Los primeros eran aquellos que no estaban inscritos en el padrón de vecindad ( $\left.\operatorname{art}^{\mathrm{o}} 7\right)$. La declaración de vecindad correspondía a los ayuntamientos. Tenían la consideración de vecinos todos los españoles cabezas de familia que en la época de formarse o rectificarse el padrón llevaran dos años de residencia fija en la localidad, ejerciendo en ella su profesión u oficio ( $\left.\operatorname{art}^{\circ} 10\right)$.

En esta Ley se señala que cuando una persona se trasladara a vivir a otro municipio debía dar aviso de este hecho al ayuntamiento en el que hasta entonces hubiera sido vecino (Arts. 11 y 14). La vecindad se perdía en el momento en que el ayuntamiento recibía aviso de que el interesado había sido inscrito en el padrón de otra localidad ( $\left.\operatorname{art}^{\mathrm{0}} 19\right)$.

La formación del padrón, o su rectificación, se produciría todos los años desde $1^{\mathrm{o}}$ de octubre a $1^{\mathrm{o}}$ de noviembre. En los quince días siguientes serían expuestos en las secretarías municipales para que los vecinos presentaran las correspondientes reclamaciones. Antes de que acabara ese mes serían resueltas por los ayuntamientos ( $\left.\operatorname{art}^{\circ} 15\right)$. Todavía durante la primera quincena de diciembre las personas que se sintieran agraviadas por esas resoluciones podrían reclamar ante las diputaciones pro-

\footnotetext{
${ }^{30}$ Gaceta de Madrid, núm. 1531, de 15 de marzo de 1857.
} 
vinciales respectivas. No en vano, los ayuntamientos estaban obligados a enviar una copia completa del padrón a su diputación provincial cada cinco años, dando cuenta de las alteraciones habidas en los años intermedios ( $\left.\operatorname{art}^{\circ} 16\right)$.

Las únicas alteraciones que podían incluirse en el padrón a lo largo del año eran las inscripciones a instancia de parte y las eliminaciones por incapacidad legal, defunción, o por haberse avecindado en otro municipio ( $\left.\operatorname{art}^{\circ} 17\right)$.

Una nueva Ley, esta vez de 17 de junio de 1870, quitó a los ayuntamientos las competencias hasta entonces ejercidas de Registro civil que pasaron a depender de la administración de justicia. Los juzgados municipales, a cargo de sus respectivos jueces, asistidos por sus secretarios, asumían las funciones de llevar los libros oficiales del Registro establecidos en el año 1841, como ya sabemos, en todas las poblaciones capitales de provincia, de partido judicial o en las que excediera su población de los quinientos vecinos.

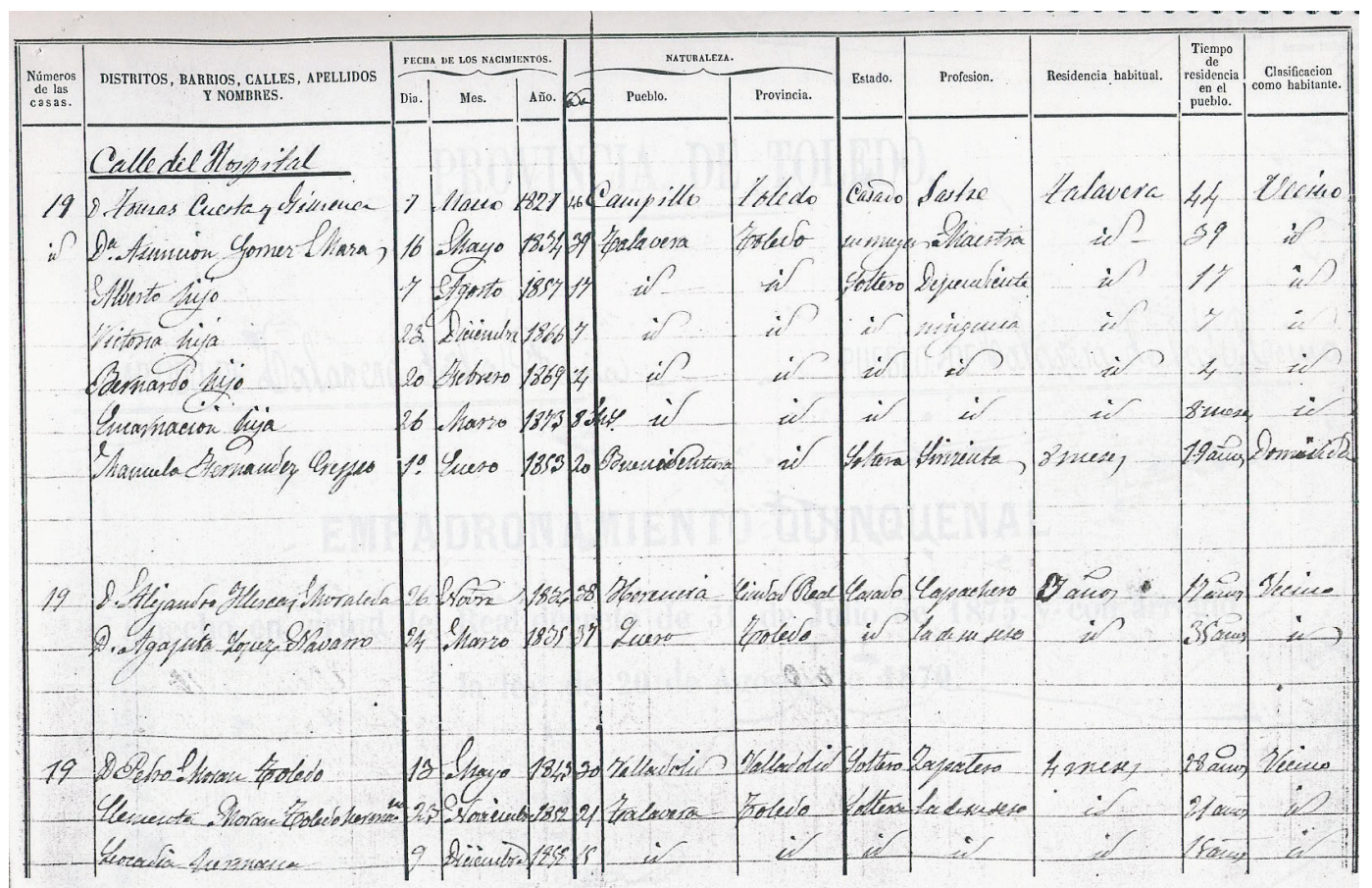

Figura 5. Hoja del padrón realizado en Toledo en 1870.

\section{LOS PADRONES DE HABITANTES QUINQUENALES (1870-1996)}

Tras la abdicación de la Reina Isabel II se aprueba una nueva Ley Municipal el 20 de agosto de 1870, que pretendió actualizar el contenido de la Ley de 1856, vigente desde finales de 1868 . En ella se clasifica a los habitantes de un término mu- 


\section{MARIANO GARCÍA RUIPÉREZ \\ EL EMPADRONAMIENTO MUNICIPAL EN ESPAÑA}

nicipal en residentes y transeúntes. Los primeros se dividían a su vez en vecinos y domiciliados ( $\left.\operatorname{art}^{\mathrm{o}} 10\right)$. Los domiciliados eran los españoles que sin estar emancipados (en clara alusión a no tener mayoría de edad u otra limitación legal) residían en un municipio formando parte de la casa o familia de un vecino.

Todos los habitantes residentes, fueran vecinos o domiciliados, debían estar empadronados. Se consideraban transeúntes a los habitantes que se encontraran accidentalmente residiendo en el municipio, y no estaban empadronados. La declaración de una persona como vecino la realizaba el ayuntamiento respectivo, bien de oficio o a instancia de parte, siempre que el primero demostrara llevar residiendo de una forma efectiva al menos seis meses en esa localidad ( $\left.\operatorname{rrt}^{\circ} 15\right)$.

La Ley Municipal de 1870 dedica íntegramente el capítulo III, de su título I, a "Del empadronamiento" (Arts. 16-22). Todos los ayuntamientos estaban obligados a formar el padrón de sus habitantes, con expresión de su calidad de vecinos, domiciliados o transeúntes, su nombre, edad, estado, profesión, residencia y demás circunstancias que el Gobierno exigiera ( $\operatorname{rrt}^{\circ} 16$ ). Cada cinco años se haría un nuevo empadronamiento, que sería rectificado anualmente con las nuevas inscripciones, las eliminaciones por incapacidad legal o defunción, y los traslados de vecindad ( $\left.\operatorname{art}^{\mathrm{o}} 17\right)$. Las eliminaciones y los traslados serían reflejadas en las oportunas declaraciones que presentarían los interesados o sus representantes ante los ayuntamientos ( $\operatorname{art}^{\mathrm{o}} 17$ ).

Verificado el empadronamiento quinquenal o su rectificación anual, los ayuntamientos formarían dos listas en extracto, que serían publicadas inmediatamente; una con las alteraciones ocurridas a lo largo del último año, y otra con todos los habitantes que resultaran inscritos en el padrón ( $\left.\operatorname{art}^{\mathrm{o}} 18\right)$.

El empadronamiento, o su rectificación, se realizaría a lo largo del mes de diciembre, así como las listas. Toda esa documentación podría ser examinada por los vecinos interesados en las secretarías de los ayuntamientos. En los primeros quince días de enero se podrían presentar las reclamaciones, quedando reflejadas las resoluciones adoptadas sobre ellas en los libros de acuerdos municipales ( $\left.\operatorname{art}^{\circ} 19\right)$. Además serían comunicadas por escrito a cada interesado. Recibida la notificación con la resolución cabía aún el recurso de alzada ante la comisión provincial, una vez enviado todo el expediente desde el ayuntamiento. La comisión tenía un mes de plazo para resolver el recurso. Sólo entonces, cuando hubieran sido resueltos los posibles recursos, podía darse por ultimado el padrón, y se procedían a hacer públicas las listas rectificadas $\left(\operatorname{art}^{\circ} 20\right)$.

Todos los años, los ayuntamientos estaban obligados a enviar, a sus respectivas diputaciones provinciales, un resumen del número de vecinos, domiciliados y 
transeúntes, que habitaran en sus localidades, clasificados con arreglo a los criterios establecidos por el Gobierno en el censo de población $\left(\operatorname{art}^{\mathrm{0}} 22\right)^{31}$.

El Consejo de Estado puso en vigor, por Real Decreto de 6 de mayo de $\mathbf{1 8 7 1}^{32}$, un reglamento para la ejecución de esta Ley Municipal de 1870. Su capítulo $2^{\circ}$ llevaba por título "De los habitantes y sus empadronamientos" con cuyo articulado pretendió aclarar algunos aspectos no debidamente desarrollados en la Ley. La declaración de vecindad se solicitaría por los interesados mediante instancia, de cuya presentación recibirían resguardo, acompañada de documentos justificativos. La resolución del expediente se produciría en el plazo más breve posible ( $\left.\operatorname{art}^{\circ} 17\right)$. La declaración de vecindad, fuera de oficio o a instancia de parte, se comunicaría por escrito al interesado dentro de las veinticuatro horas de acordada, haciéndole firmar el recibo de la comunicación ( $\left.\operatorname{art}^{\mathrm{o}} 19\right)$.

Pero además de regular el expediente de declaración de vecindad, con este Reglamento se estableció, por su artículo 21, el modelo oficial de la hoja del padrón de habitantes. Cada cabeza de familia debía recibir una hoja para que rellenara las correspondientes casillas, bajo la amenaza de multa si no lo ejecutaba $\left(\operatorname{art}^{\mathrm{o}} 22\right)$.

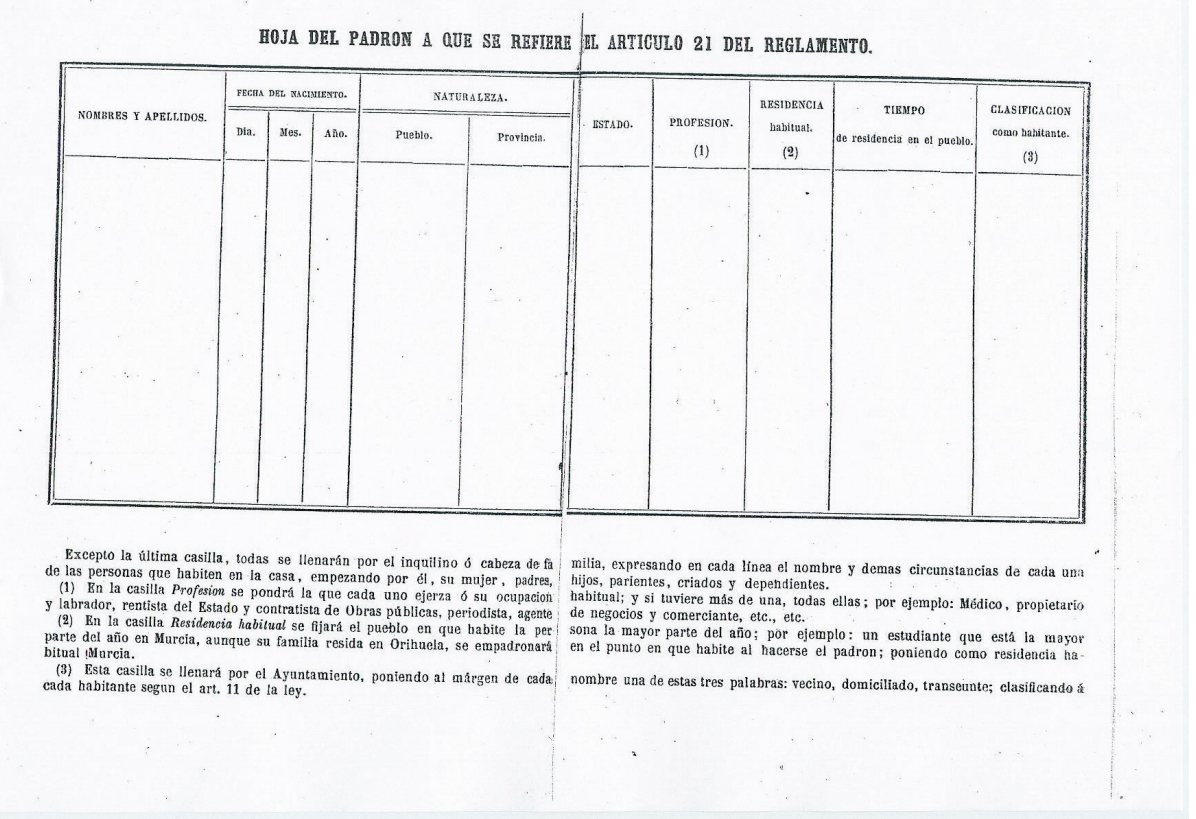

Figura 6. Modelo oficial de la hoja del padrón municipal de habitantes de 1871 aprobada por Decreto de 6 de mayo de 1871.

\footnotetext{
${ }^{31}$ En esta importante Ley, en su art. 21, se define el padrón como "un instrumento solemne, público y fehaciente, que sirve para todos los efectos administrativos". Véase Legislación administrativa española del siglo XIX, p. 856.

${ }^{32}$ Gaceta de Madrid de 7 de mayo de 1871.
} 


\section{MARIANO GARCÍA RUIPÉREZ \\ EL EMPADRONAMIENTO MUNICIPAL EN ESPAÑA}

La realización de las rectificaciones anuales del padrón se llevaría a cabo con las declaraciones de cambio de domicilio, incapacidad o defunción que los alcaldes exigirían a los interesados o responsables, y a los jueces municipales como encargados del Registro civil ( $\left.\operatorname{art}^{\circ} 23\right)$. La falsedad de los datos aportados podría dar lugar a procedimientos penales ( $\left.\operatorname{art}^{\mathrm{o}} 24\right)$. La condición de vecino podía demostrarse por la inclusión en el padrón respectivo o con una certificación "en forma que acredite el día en que el interesado obtuvo la declaración de vecindad" ( $\left.\operatorname{art}^{\circ} 25\right)$.

El fin de la primera República, tras el pronunciamiento del general Martínez Campos, en Sagunto, el 29 de diciembre de 1874, supuso el inicio de un largo periodo histórico conocido como la Restauración. La Ley de Ayuntamientos de 1870 apenas sufrirá cambios durante las décadas siguientes en el tema que nos ocupa. Las principales modificaciones de esta disposición serían recogidas en la Ley de 16 de diciembre de 1876 que en lo relativo al empadronamiento determinaba la asunción directa por parte de las diputaciones provinciales de las competencias dadas en el arto 20 a las comisiones provinciales ${ }^{33}$. De ahí que la Ley Municipal de 2 de octubre de 1877 recoja el texto íntegro del articulado de la Ley de 1870, con el único cambio ya mencionado ${ }^{34}$.

No cabe duda de que la principal innovación de la Ley de 20 de agosto de 1870 fue el establecimiento del empadronamiento quinquenal. La primera norma aprobada para su regulación durante la Restauración fue el Real Decreto del Ministerio de la Gobernación de 31 de julio de $1875^{35}$. Todos los pueblos de España estaban obligados a ejecutarlo en un día concreto ( $\left.\operatorname{art}^{\mathrm{o}} 1\right)$. Todos los cabezas de familia o habitantes con casa abierta estaban obligados a "llenar escrupulosamente el padrón en blanco" que les habrían facilitado días antes los dependientes del municipio. Solo si no sabían escribir o estaban imposibilitados podían delegar en un tercero para que firmara en su nombre ( $\operatorname{art}^{\mathrm{0}} 2$ ). De esta obligación no estaban exentos los fondistas, posaderos, mesoneros y dueños de establecimientos en donde pernoctaran personas ajenas a la familia, dado que el padrón incluiría también a los transeúntes ( $\operatorname{art}{ }^{\circ} 3$ ). Su condición quedaría reflejada en la columna de "Observaciones". También esta casilla sería cumplimentada por los varones de 19 a 35 años, dado que tendrían que indicar si estaban exentos o no de cumplir el servicio militar.

\footnotetext{
${ }^{33}$ Legislación administrativa española del siglo XIX, p. 887. En concreto así se determina en su disposición sexta.

${ }^{34}$ La otra modificación es la variación en el número de los artículos de este capítulo III, que en el caso de la Ley Municipal de 1877 abarca desde el artículo 17 al 23.

${ }^{35}$ Este Real Decreto aparece reproducido en el Boletín Oficial de la Provincia de Toledo de 3 de agosto de 1875 .
} 


\section{MARIANO GARCÍA RUIPÉREZ \\ EL EMPADRONAMIENTO MUNICIPAL EN ESPAÑA}

En el artículo 5 de este Real Decreto de 1875 se establece que "todas las cédulas o padrones que se entreguen a los vecinos estarán numeradas correlativamente con arreglo a una lista general por barrios y calles" formada por los ayuntamientos. Las cédulas serían distribuidas entre los vecinos por repartidores designados, aunque en las casas de campo y despoblados lo efectuarían la Guardia Civil, la rural o los guardas de montes. También a ellos competía su posterior recogida.

El empadronamiento ordenado por este Real Decreto debía estar terminado el día 31 de agosto de 1875 .

En los años siguientes no se producirán cambios significativos en la normativa sobre el empadronamiento. Una Real Orden de 14 de octubre de 1884 insistió en la importancia de realizar las rectificaciones anuales del padrón, considerando falta grave su omisión. Otro Real Decreto de 24 de marzo de 1891 recordó la vigencia de las disposiciones aprobadas en 1870 y 1871, y exigió a los gobernadores que exigieran a los ayuntamientos que por su conducto remitieran el resumen clasificado del número de habitantes de cada término municipal a su respectiva diputación provincial.

Por la Ley de 2 de mayo de 1889 se ordenó la realización de un nuevo empadronamiento, que debía estar concluido en la primera semana de agosto de ese año. Hasta entonces se había realizado en los años terminados en 0 y $5^{36}$.

La formalización de los censos de la población de España, tras el inicial de 1857, se llevó a cabo con arreglo a su propia normativa. Para ello se constituyeron en esas décadas juntas municipales y provinciales del Censo de la Población. Las primeras eran presididas por los alcaldes respectivos y estaban integradas, entre otros, por todos los concejales de cada ayuntamiento.

Las juntas municipales aparecen ya claramente reguladas en una Instrucción de 20 de septiembre de 1887. Fueron reorganizadas por el artículo 2 de la Instrucción de 9 de noviembre de 1897 y por los artículos 7 y 8 de la de 6 de julio de 1900 . Llevaban sus propios libros de acuerdos ( $\operatorname{art}^{\circ} 10$ de esta última instrucción) y eran las encargadas de la aplicación en sus términos municipales de la normativa censal. Para el empadronamiento de todos los habitantes se utilizaban "cédulas de inscripción", bien de familia o colectivas, distinguidas por colores, entregadas en cada vivienda o establecimiento (conventos, hospitales, cuarteles...) por agentes repartidores.

En el Censo de Población realizado con fecha de 31 de diciembre de 1900 ya se distinguía a los residentes presentes, a los residentes ausentes y a los transeúntes, constituyendo los dos primeros la población de derecho. La de hecho estaba formada

\footnotetext{
${ }^{36}$ Gaceta de Madrid de 3 de mayo de 1889.
} 


\section{MARIANO GARCÍA RUIPÉREZ \\ EL EMPADRONAMIENTO MUNICIPAL EN ESPAÑA}

por los residentes presentes y los transeúntes. En las cédulas de inscripción se incluían casillas para el nombre completo, edad, sexo, estado civil, instrucción elemental, naturaleza, nacionalidad y profesión. Los datos de las cédulas, una vez recogidas y corregidas, eran asentados en extracto en un cuaderno auxiliar, y en distintos resúmenes. La junta municipal procedía a continuación a "formar el padrón de habitantes, copiando para ello en las hojas impresas que a tal fin se le hubieren remitido, el contenido de todas las cédulas recogidas, debiendo tenerse en cuenta, por lo tanto que es necesaria una línea del padrón por habitante" ( $\operatorname{art}^{\mathrm{o}} 38$ de la Instrucción de 6 de julio de 1900).

En ese mismo artículo se establece que si el término municipal a efectos censales se había dividido en distintas secciones, así se distribuiría la información en el padrón. Las cédulas de inscripción se copiarían dentro de su sección respectiva correlativamente por orden numérico, sin dejar claros entre cédula y cédula. Una vez concluida esta tarea, se foliaría el padrón resultante, dividido según las secciones, y se incluiría, al final, un resumen numérico autorizado con la firma de los miembros de la Junta. Todos los documentos producidos (cédulas de inscripción, cuadernos auxiliares, resúmenes, padrón de habitantes, memoria, cuenta de gastos, etc.) debían ser entregados por las juntas municipales a las provinciales para su examen y comprobación ( $\operatorname{art}^{\mathrm{o}} 39$ ). Verificada ésta serían devueltos a cada ayuntamiento tanto el cuaderno auxiliar, como el padrón o los resúmenes numéricos ( $\left.\operatorname{art}^{\circ} 42\right)$. Las cédulas originales quedaban en poder de las juntas provinciales del Censo de Población.

Por la Ley de 3 de abril de $\mathbf{1 9 0 0}$ quedó establecido que se realizara el Censo de Población de España el 31 de diciembre de ese año y que los empadronamientos sucesivos tuvieran lugar cada diez años en igual día. Obviamente la realización del Censo implicaba también la formación del padrón municipal de habitantes, de tal forma que a partir de entonces, si no antes, en el último día de los años terminados en cinco, se hacía sólo el padrón, mientras que en los años terminados en cero se formalizaba el censo, y con su información se obtenía el padrón quinquenal establecido por la legislación desde la Ley Municipal de 1870. Esta norma estuvo en vigor en lo relativo al empadronamiento hasta la aprobación del Estatuto Municipal de 8 de marzo de 1924.

La normativa sobre empadronamiento establecida en 1870, y ratificada en 1877, en las respectivas leyes municipales, estuvo vigente hasta la aprobación del Estatuto Municipal de 8 de marzo de 1924. Su Libro primero, Título III, lleva por título "De la población y de su empadronamiento" (artículos 26-37). En cuanto a la clasificación de los habitantes de un municipio distingue entre los cabezas de familia, vecinos, domiciliados y transeúntes ( $\operatorname{rrt}^{\mathrm{o}} 26$ ), por lo que introduce cambios con 


\section{MARIANO GARCÍA RUIPÉREZ \\ EL EMPADRONAMIENTO MUNICIPAL EN ESPAÑA}

respecto a la normativa de 1877 . El cabeza de familia era el representante legal de su casa, y podía ser o no vecino ( $\left.\operatorname{art}^{\circ} 27\right)$. En el artículo 33 se establece la confección cada cinco años del padrón municipal, y su rectificación anual "con las inscripciones y eliminaciones que procedan”. Esas operaciones se llevarían a cabo durante el mes de diciembre por la Comisión Municipal Permanente. Los documentos resultantes se expondrían al público durante quince días y de su contenido cabía presentar reclamaciones ante la propia Comisión. Contra el acuerdo de ésta se podía elevar recurso ante el Jefe Provincial de Estadística, cuya resolución era firme y ejecutiva ( $\operatorname{art}^{\circ} 33$ ). La declaración de vecindad, de oficio o a instancia de parte, recaía en esa Comisión Municipal sin que se produjeran cambios en los plazos de residencia establecidos en la legislación anterior ( $\operatorname{rrt}^{\mathrm{o}} 36$ ). Por último se obligaba a los ayuntamientos a enviar todos los años, antes del 30 de abril, un resumen numérico del padrón municipal de habitantes a la Dirección General de Estadística ( $\left.\operatorname{art}^{\mathrm{o}} 37\right)^{37}$.

Un Real Decreto de 2 de julio de 1924, del Directorio Militar, aprobó el Reglamento sobre Población y Términos Municipales. Su Título V, Capítulo II, está dedicado a "Del empadronamiento" (artículos 33-49).

Se inicia su articulado indicando la obligatoriedad de inscripción en el padrón de todos los habitantes de un término municipal, con la expresión de su calidad (cabeza de familia, vecino, domiciliado o transeúnte), nombre y dos apellidos, fecha de nacimiento, naturaleza, nacionalidad, estado civil, residencia, profesión, renta, sueldo o remuneración y demás circunstancias que el Censo de Población determinase ( $\operatorname{art}^{\circ} 33$ ). De su confección quinquenal, y su rectificación anual, trata el artículo 34. Para su elaboración se distribuiría una hoja, según un modelo que entonces se aprobó y circuló con el Reglamento, a cada cabeza de familia encargado de rellenar todas las casillas salvo la relativa a la clasificación de los habitantes, que lo haría el Ayuntamiento ( $\left.\operatorname{art}^{\mathrm{o}} 35\right)$.

Las rectificaciones anuales se llevarían a cabo con las declaraciones que debían exigir los alcaldes a las personas que cambiaran de domicilio, a los padres o tutores de los que resultaran incapacitados legalmente, y a los familiares de los fallecidos, contando además con la información que podía suministrar el Registro Civil, si el ayuntamiento lo solicitara de personas determinadas ( $\operatorname{art}^{\mathrm{o}} 36$ y 45).

Tanto el padrón como su rectificación estarían a disposición de cuantos quisieran examinarlo en las secretarías municipales los días y horas útiles ( $\operatorname{art}^{\mathrm{o}} 37$ ). Las reclamaciones podían presentarse durante los primeros quince días de enero y sería

${ }^{37}$ En el artículo 150 del Estatuto Municipal de 1924 se reconoce que es de exclusiva competencia municipal la "Formación, rectificación y custodia del padrón municipal, y cuanto se refiera a ad- 


\section{MARIANO GARCÍA RUIPÉREZ \\ EL EMPADRONAMIENTO MUNICIPAL EN ESPAÑA}

la Comisión Municipal Permanente la encargada de su resolución, reflejando el acuerdo hecho en su libro de actas ( $\left.\operatorname{art}^{\circ} 38\right)$. Los plazos se amplían hasta un mes para las ciudades de más de cien mil habitantes. Contra los acuerdos de esa Comisión se podía recurrir ante el Jefe provincial de Estadística ( $\operatorname{art}^{\mathrm{o}} 39$ ) presentando el recurso ante aquella en los tres días siguientes de la recepción de la notificación. Recibido todo el expediente en la Sección provincial de Estadística, su Jefe resolvería en un plazo de quince días. Una vez comunicada su resolución, y hechas en la semana siguiente las rectificaciones oportunas del padrón, se declararía ultimado ( $\operatorname{art}^{\circ} 40$ ). Tanto el padrón como sus rectificaciones tenían que presentarse ante esa Sección, que consignaría la diligencia de aprobación con el sello y la firma de su Jefe (art ${ }^{\circ}$ 42).

La negativa a rellenar la hoja del padrón podía dar lugar a la imposición de multas gubernativas, $\mathrm{y}$ al inicio de otros procedimientos judiciales $\left(\operatorname{art}^{\mathrm{o}} 43\right)^{38}$.

Los expedientes de declaración de vecindad a instancia de parte se iniciarían con la solicitud del interesado dirigida a la Comisión Municipal Permanente, acompañada de documentos que acreditaran su residencia efectiva al menos durante seis meses ( $\left.\operatorname{art}^{\circ} 45\right)$. La Comisión las resolvería en un plazo de quince días, y su acuerdo sería notificado al interesado dentro de los tres días siguientes que podía previamente recibir un resguardo numerado que acreditara la presentación de esa documentación $\left(\operatorname{art}^{\circ} 46\right)$.

El artículo 47 del Reglamento se detiene en la estructura del resumen del padrón de habitantes que comprendería separadamente el de la población de hecho (número de residentes presentes y transeúntes, por sexos, y con distinción entre vecinos, domiciliados y transeúntes), y el de la población de derecho (número de residentes presentes y ausentes, por sexos, distinguiendo los vecinos y domiciliados). En este resumen se daría cuenta también separadamente del número total de militares, y de los que residían en establecimientos hospitalarios y asistenciales. La Dirección General de Estadística podía pedir a los ayuntamientos una copia de todo, o de parte, del padrón de habitantes o de su rectificación.

Terminaba este texto legal indicando que con carácter excepcional el siguiente padrón se formaría en el mes de diciembre de 1924, teniendo una vigencia de seis años ( $\left.\operatorname{art}^{\circ} 49\right)$. Para su formalización, con fecha de $1^{\circ}$ de diciembre, se aprobó la Instrucción de 14 de noviembre de $1924^{39}$. El procedimiento a seguir en la inscripción

\footnotetext{
quisición, pérdida o comprobación de la ciudadanía municipal”.

${ }^{38}$ También el Reglamento de Población de 1952 recogió en su artículo 95.5 la posibilidad de imposición de multas a los que no rellenaran las hojas padronales.

${ }^{39}$ Gaceta de Madrid de 22 de noviembre de 1924.
} 


\section{MARIANO GARCÍA RUIPÉREZ \\ EL EMPADRONAMIENTO MUNICIPAL EN ESPAÑA}

y formación del padrón está contemplado en los artículos 8-26). El reparto de las "hojas de inscripción", y la forma de ser rellenadas, está regulado en los artículos 911. La justificación de la residencia efectiva durante un plazo concreto se podía realizar mediante una certificación referida a la inclusión de esa persona en el padrón de habitantes, una certificación referida al padrón de cédulas personales, una certificación de su inclusión en el censo electoral, una certificación del registro de expedición de carnets de identidad, un contrato de inquilinato, y una información testifical ante el juez municipal, entre otros documentos ( $\left.\operatorname{art}^{\circ} 17\right)$

Con esta Instrucción se aprobaron nuevos modelos oficiales de hoja de inscripción, de hoja padronal ( $\left.\operatorname{art}^{\circ} 18\right)$, de "cuaderno auxiliar" ( $\left.\operatorname{art}^{\mathrm{o}} 19\right)$ y de "resumen del padrón municipal" $\left(\operatorname{art}^{\mathrm{o}} 19\right)^{40}$.

Tras la proclamación de la II República, el 14 de abril de 1931, quedó derogado el Estatuto Municipal de 1924, que fue sustituido por la Ley de Ayuntamientos de 1877. Pero esto no afectó al "empadronamiento municipal" dado que un Decreto de 16 de junio de 1931, del Ministerio de la Gobernación, declaró vigente el Reglamento de Población de 1924 prácticamente en su totalidad.

En la Ley de Bases de 10 de julio de 1935 se dedica su base III a "De la población y su empadronamiento", aunque se detiene casi exclusivamente en la distinción entre cabezas de familia, vecinos, domiciliados y transeúntes. Como desarrollo de esta Ley se aprobó su Texto articulado el 31 de octubre de 1935. Esta ley municipal republicana fue sacada adelante con el apoyo parlamentario de las fuerzas políticas de la derecha presentes en las Cortes. La sección primera de su capítulo III lleva el consabido título de "De la población y su empadronamiento", abarcando los artículos 30-34. De su contenido nos llama la atención que en su artículo 33 se defina el padrón municipal, "instrumento público y fehaciente para todos los efectos administrativos", como "la relación calificada de los habitantes de un término municipal". Además, tras referirse a la renovación quinquenal, y a la rectificación anual, establece que la renovación consistiría en hacer un nuevo empadronamiento, mientras que las rectificaciones se concretarían documentalmente en apéndices a ese padrón formados por las altas y las bajas acordadas por los ayuntamientos junto con las demás alteraciones producidas ( $\operatorname{art}^{\mathrm{o}} 34$ ). No hay novedad en la fecha de referencia (31 de diciembre), tampoco en su exposición pública, ni en que los recursos sobre su inclusión o exclusión fueran resueltos por el Jefe provincial de Estadística. Incluye, eso sí, la necesidad de realizar resúmenes numéricos de toda renovación o rectificación, por

${ }^{40}$ Estatuto Municipal de 8 de marzo de $1924 \ldots$ con los reglamentos complementarios..., $2^{\mathrm{a}}$ edición, Madrid, 1925. Los modelos oficiales se reproducen en las páginas 736-745. 
triplicado, que debían enviarse a la Sección Provincial de Estadística, para su conformidad, si procedía. Dos de esos resúmenes serían enviados, uno al ayuntamiento y otro al Ministerio de la Gobernación ( $\left.\operatorname{art}^{\mathrm{0}} 34\right)$.

Esta norma tuvo vigencia hasta la aprobación de la Ley de Bases de 17 de julio de 1945. Su base $5^{\text {a }}$ lleva por título "De la población municipal", y en ella se recoge la obligación que tenían todos los residentes de estar empadronados, y se recuerdan los requisitos de residencia para la declaración de vecindad (dos años, si era de oficio, o seis meses, si era de parte).

Un Decreto de 24 de diciembre de $\mathbf{1 9 4 5}^{41}$ ordenó la renovación de los padrones municipales de habitantes y estableció un Registro estadístico de residentes mayores de edad para facilitar los procesos electorales. Por el artículo 3 de esta disposición se ordenó la entrega en cada domicilio o familia de dos "hojas de inscripción" idénticas que debían ser rellenadas con los mismos datos. Formadas dos colecciones con las hojas señaladas, ordenadas por distritos y barrios, una de ellas "formará el documento original para la redacción del Padrón de Habitantes". La otra sería entregada en las respectivas Secciones provinciales de Estadística para formar con ellas el registro de residentes mayores de edad.

Pero las variaciones habidas a lo largo del año se anotaban al final de éste, al hacer la rectificación del padrón, y no conforme se iban produciendo, por lo que era imposible, salvo en esa fecha concreta, conocer el número y situación real de los habitantes de cada localidad. Para modificar esta situación, y en aplicación de algunos de los preceptos contemplados en la Ley de Estadística de 31 de diciembre de $1945^{42}$, fue aprobado un nuevo Decreto, esta vez de 24 de marzo de 1949, en el que se recordaba la obligatoriedad que tenían todos los habitantes de estar inscritos en los respectivos padrones municipales. Todas las variaciones quedarían reflejadas en las correspondientes declaraciones de altas, bajas, y cambios de domicilio que serían comunicadas a los ayuntamientos conforme se fueran produciendo. Esas declaraciones serían registradas y archivadas ordenadamente para que sirvieran de base en la realización de la rectificación anual $\left(\operatorname{art}^{\mathrm{0}} 3\right)^{43}$.

${ }^{41}$ Boletín Oficial del Estado de 29 de diciembre de 1945. En esta disposición se describe la renovación padronal de la siguiente manera: "se inicia mediante el reparto de hojas por las viviendas, y su recogida una vez cubiertas; luego procede su estudio y depuración, calificación municipal de inscritos, exposición para reclamaciones, resolución de éstas, y aprobación final por los Jefes provinciales de Estadística".

${ }^{42}$ El reglamento de esta Ley fue aprobado por Decreto de 2 de febrero de 1948, publicado en el Boletín Oficial del Estado de 2 de abril de 1948. En los artículos 5 y 7.c se establecen las competencias del INE en materia de padrones municipales.

${ }^{43}$ Boletín Oficial del Estado de 30 de marzo de 1949. 


\section{MARIANO GARCÍA RUIPÉREZ \\ EL EMPADRONAMIENTO MUNICIPAL EN ESPAÑA}

\section{El Texto articulado de la Ley de Régimen Local de 16 de diciembre de} 1950 dedica su Título segundo, que abarca del artículo 41 al 57, a "De la población municipal y de su empadronamiento". De nuevo clasifica a los habitantes de un municipio en residentes y transeúntes. Los primeros a su vez podían ser cabezas de familia, vecinos y domiciliados. Todo español o extranjero que viviera en España debía estar empadronado en un solo municipio ( $\operatorname{art}^{\circ} 50$ ). El padrón sería formado por los ayuntamientos cada cinco años, y rectificado anualmente, con referencia a 31 de diciembre ( $\left.\operatorname{art}^{\circ} 51\right)$. Tras la distinción entre población de hecho y de derecho define el padrón como "la relación de los habitantes del término (municipal), con expresión de las respectivas calidades" ( $\operatorname{art}^{\mathrm{o}} 52$ ). En él debían figurar los nombres, apellidos, edad y naturaleza, profesión u ocupación, estado civil de cada habitante, parentesco con el cabeza de familia y cuantos datos aseguraran la mejor clasificación de la población ( $\left.\operatorname{art}^{\circ} 52\right)$.

La declaración de vecindad la realizaba de oficio el alcalde a favor de todos los españoles mayores de edad que llevaran residiendo por lo menos dos años en el municipio, al formarse o rectificarse el padrón. Y se realizaba a instancia de parte para todos aquellos que lo solicitaran y demostraran llevar residiendo seis meses de continuo en el municipio ( $\left.\operatorname{art}^{\circ} 53\right)$.

En el Texto articulado se indica, además, que el padrón y sus apéndices (que no se especifican) serían expuestos al público ( $\operatorname{art}^{\circ} 56$ ). Además de las inclusiones, exclusiones o calificación de los habitantes en el empadronamiento se podía reclamar ante el alcalde, para después, si era el caso, elevar recurso de alzada ante el Gobernador Civil de la Provincia, que resolvería tras informe de la Delegación Provincial del Instituto Nacional de Estadística ( $\operatorname{art}^{\circ}$ 56.2). La aprobación definitiva del padrón correspondería a esa misma Delegación ( $\operatorname{art}^{0} 57.2$ ).

En realidad, el empadronamiento municipal apenas había sufrido variaciones desde la aprobación del Estatuto Municipal y de su Reglamento de Población en el año de 1924. Cambios significativos serán introducidos por el régimen franquista, tras aprobar su Ley de Bases en 1945 y su Texto articulado en 1950, en su nuevo Reglamento de Población y Demarcación Territorial de las Entidades Locales, aprobado por Decreto de 17 de mayo de $\mathbf{1 9 5 2}^{44}$. Dentro de su Título III dedica su capítulo segundo a "Del empadronamiento municipal" (arts. 91-119) en la línea ya comentada del Texto articulado. En el padrón se incluirían, de cada habitante, los datos siguientes: a) Nombre y apellidos, b) Sexo, c) Fecha de nacimiento y lugar donde hubiere acontecido, d) Estado civil, e) Parentesco o relación con el cabeza de

\footnotetext{
${ }^{44}$ Boletín Oficial del Estado, número 164, de 12 de junio de 1952.
} 


\section{MARIANO GARCÍA RUIPÉREZ \\ EL EMPADRONAMIENTO MUNICIPAL EN ESPAÑA}

familia, f) Si sabe o no leer y escribir, g) Profesión, oficio u ocupación, y h) Cuantas otras circunstancias tiendan a asegurar la clasificación ( $\left.\operatorname{art}^{\circ} 92\right)$. En relación con el Reglamento de 1924 el principal cambio es la sustitución del apartado relativo a "renta, sueldo o remuneración" por "si sabe o no leer y escribir".

Las hojas de inscripción en el Censo de Población incluirían todos esos datos que podían ser utilizados por los ayuntamientos para formar el padrón de población ( $\operatorname{art}^{\circ}$ 93.2). La fecha de su formación coincidiría con la del Censo en los años en que éste se llevara a cabo ( $\operatorname{art}^{\circ}$ 94.4), si bien, entonces, se debían cumplimentar tanto las hojas de inscripción en el Censo como las hojas de formación del padrón municipal $\left(\operatorname{art}^{0}\right.$ 95.4).

Las variaciones que se fueran produciendo respecto de cada inscrito se anotarían inmediatamente, se resumirían cada mes, y de ellas se daría cuenta en los diez primeros días del mes siguiente a la Delegación Provincial del Instituto Nacional de Estadística ( art $^{\circ}$ 94.1).

Para la formación, renovación y rectificación del padrón ( $\left.\operatorname{art}^{\circ} 95\right)$ se distribuirían hojas impresas, ajustadas al modelo oficial, que debían ser cumplimentadas por los cabezas de familia. A esas hojas se podían añadir otras adicionales si en el transcurso del año aumentase el número de personas que vivieran bajo un mismo techo.

De la obligación de comunicar a la alcaldía los cambios de residencia, domicilio o estado civil que realizaran los residentes de un municipio trata el artículo 97. La incapacidad legal o el fallecimiento sería reflejada en el padrón tras la presentación por sus tutores o parientes de las respectivas declaraciones ( $\left.\operatorname{art}^{\circ} 98\right)$. Los alcaldes, además, podían reclamar al Registro Civil, cuantos datos estimaran necesarios sobre personas determinadas ( $\operatorname{art}^{\circ} 99$ ).

Toda persona que trasladara su residencia a otro municipio estaba obligada a presentar una declaración por duplicado ante el ayuntamiento de origen. Uno de los ejemplares le sería devuelto, autorizado mediante diligencia y con el sello correspondiente, para acreditar su baja provisional ( $\operatorname{art}^{\mathrm{o}} 109$ ). Este documento lo acompañaría a la solicitud de alta que debía presentar en el ayuntamiento de destino. En ese momento quedaría inscrito en éste como transeúnte, aunque transcurridos seis meses, a su instancia, o dos años, de oficio, alcanzaría la condición de residente. Lograda esta calificación, el alcalde debía comunicarla al del municipio de procedencia para que fuera dado de baja definitivamente en el padrón del mismo ( $\left.\operatorname{art}^{\circ} 111\right)$ perdiendo la condición de residente ausente que había obtenido al comunicar su traslado a otra localidad.

Ningún cambio se produce en los plazos de declaración de vecindad ( $\left.\operatorname{art}^{\circ} 102\right)$. El alcalde debía resolverlas, cuando eran a petición de parte, en un plazo máximo de 
quince días, y su notificación debían recibirlas los interesados dentro de los tres días siguientes ( $\left.\operatorname{art}^{\mathrm{o}} 112\right)$. Hasta entonces esta tarea había sido competencia de la Comisión Municipal Permanente. Tampoco hay variaciones en lo relacionado con la exposición al público del padrón y de sus apéndices ( $\operatorname{art}^{\circ} 103$ ).

El plazo de presentación de reclamaciones por la inclusión, exclusión o calificación de los habitantes sería de quince días naturales. El Alcalde en los quince días siguientes resolvería las reclamaciones, que serían recogidas en el Libro de decretos y resoluciones ( art $^{\mathrm{o}} 104$ ), aunque estos plazos se ampliaban hasta un mes en los municipios de más de 100.000 habitantes ( $\operatorname{art}^{\circ} 105$ ). Tras recibir la notificación de esa resolución, los interesados tenían un plazo de tres días para presentar en la Alcaldía un recurso de alzada ante el Gobernador Civil. El alcalde, con su informe, remitiría esos expedientes ante la autoridad provincial, que para resolver debía trasladarlos al Delegado provincial del Instituto Nacional de Estadística (INE). Éste, tras su estudio, formularía la propuesta al Gobernador Civil, que debía dictar una resolución motivada en término de quince días ( $\left.\operatorname{art}^{\mathrm{o}} 106\right)^{45}$.

La aprobación definitiva del padrón seguía correspondiendo al Delegado provincial del Instituto Nacional de Estadística ( $\operatorname{rrt}^{0} 108$ ). Todos los meses, antes del día 10, los ayuntamientos remitirían a esa Delegación una relación de las altas y bajas registradas durante el mes anterior, con un resumen numérico, incluyendo su incidencia en el total de la población de hecho y de derecho de cada municipio.

El artículo 114 de este Reglamento se detiene en el contenido del "resumen del Padrón de habitantes", que comprendería separadamente el de la población de hecho (número de residentes presentes y transeúntes, por sexos, y con distinción entre vecinos, domiciliados y transeúntes), y el de la población de derecho (número de residentes presentes y ausentes, por sexos, distinguiendo los vecinos y domiciliados). En este resumen se daría cuenta también separadamente del número total de militares, y de los que residían en establecimientos hospitalarios y asistenciales.

Antes de cada 30 de abril, tanto el padrón con su cuaderno auxiliar, como las rectificaciones de ambos, según correspondiera, junto con el resumen comentado, por triplicado, serían enviados por la alcaldía la Delegación provincial del INE. Tras su examen, si era el caso, se incluiría una diligencia de aprobación con la firma y sello del Delegado ( $\left.\operatorname{art}^{\circ} 115\right)$. Un ejemplar del resumen sería devuelto al ayuntamien-

\footnotetext{
${ }^{45}$ Por este Reglamento se establecieron los "boletines municipales" de defunción, nacimiento o matrimonio. Estos boletines los firmaban los interesados (familiares del fallecido, padre o madre del nacido, contrayentes) y eran remitidos desde el Registro Civil de inscripción al Ayuntamiento en donde estuvieran empadronados. Estuvieron en vigor, con su formato y colores característicos, desde el año 1952 hasta la aprobación del Reglamento de 1986.
} 


\section{MARIANO GARCÍA RUIPÉREZ \\ EL EMPADRONAMIENTO MUNICIPAL EN ESPAÑA}

to de origen, y otro sería remitido a la Dirección General de Administración Local $\left(\operatorname{art}^{\mathrm{o}} 115\right)$.

Termina este Reglamento señalando que en todas las poblaciones con más de 5.000 habitantes de derecho debían llevarse ficheros, en los que constaran por individuo los datos del padrón municipal, y las sucesivas modificaciones habidas tras su inscripción ( $\left.\operatorname{art}^{\mathrm{o}} 119\right)$.

Pocos cambios introduce, pues, este texto legal con respecto al Reglamento aprobado en $1924^{46}$.

El Decreto de 24 de junio de $\mathbf{1 9 5 5}^{\mathbf{4 7}}$ por el que se aprueba el Texto articulado y refundido de las Leyes de Bases de Régimen Local de 17 de julio de 1945 y de 3 de diciembre de 1953 dedica su capítulo II (Arts. 50-57) a "Del empadronamiento municipal", con el mismo contenido y numeración del articulado recogido en el Texto articulado de 1950.

La situación descrita estará vigente sin modificaciones significativas hasta la aprobación del Decreto núm. 65 de 14 de enero de $1971^{48}$, del Ministerio de la Gobernación, por el que se modificaban los artículos 80 a 119 del Reglamento de Población y Demarcación de las Entidades Locales de 1952. Su objetivo era conseguir una mayor exactitud en las cifras de inscripción padronal, especialmente con el tratamiento dado a la población transeúnte, y facilitar con el cambio de la estructura del padrón la obtención y manejo de sus datos y resultados por medio de "modernos procedimientos electrónicos".

En esta disposición, tras aclarar el concepto de residente ( $\left.\operatorname{art}^{\circ} 80\right)$ y de transeúnte ( $\left.\operatorname{art}^{\circ} 81\right)$ se establece el procedimiento a seguir cuando una persona cambiaba de residencia ( $\operatorname{rrt}^{\circ} 82$ ). La clasificación de los residentes en cabezas de familia, vecinos o domiciliados ( $\left.\operatorname{art}^{\mathrm{o}} 84\right)$ no sufrió variaciones con respecto a la normativa anterior, ni lo relacionado con la calificación de extranjeros, o con la adquisición de la vecindad por los funcionarios públicos. Tampoco la definición ya conocida del padrón municipal ( $\operatorname{art}^{\mathrm{0}} 89$ ), ni la obligatoriedad de inscripción de todos los españoles o de los extranjeros que vivieran habitualmente en España ( $\left.\operatorname{art}^{\circ} 90\right)$. Su contenido se recuerda en el artículo 91. El padrón municipal de habitantes contendría respecto de todos y cada uno de los habitantes del término los siguientes datos: a) Nombre y apellidos; b) Sexo; c) Fecha y lugar de nacimiento; d) Nacionalidad; e) Estado civil;

\footnotetext{
${ }^{46}$ Una circular de la Dirección General de Estadística, de enero de 1954, difundió las instrucciones técnicas para la renovación, conservación y notificación del padrón municipal de habitantes con arreglo a la normativa establecida por el Reglamento de 1952.

${ }^{47}$ Boletín Oficial del Estado de 10 de julio de 1955.

${ }^{48}$ Boletín Oficial del Estado de 23 de enero de 1971.
} 


\section{MARIANO GARCÍA RUIPÉREZ \\ EL EMPADRONAMIENTO MUNICIPAL EN ESPAÑA}

f) Instrucción elemental; g) Profesión, oficio u ocupación; h) Parentesco o relación con el cabeza de familia; i) Domicilio, con expresión de calle, número, planta y vivienda; j) Tiempo de residencia en el municipio; y k) Cuantas otras estime útiles el ayuntamiento y permitan asegurar la clasificación vecinal.

La renovación padronal se llevaría a cabo todos los años terminados en cero y cinco, mediante la inscripción de todos los habitantes del término municipal en las hojas de inscripción, con arreglo al modelo aprobado por el INE ( $\operatorname{art}^{\circ}$ 93.1). De su reparto domiciliario y de la cumplimentación de las casillas trata el artículo 95. El incumplimiento podía dar lugar a la imposición de multas o al inicio de procedimientos judiciales ( $\operatorname{art}^{0}$ 95.4). La colaboración del Registro Civil para casos determinados está establecida en el artículo 96.

Recogidas y comprobadas las hojas de inscripción de la renovación padronal, se ordenarían y numerarían correlativamente por distritos, secciones, manzanas, calles, edificios y viviendas. A continuación se consignaría en ellas la calificación vecinal de las personas inscritas, aprobada por el alcalde o concejal delegado. Las hojas, así diligenciadas y ordenadas, con los resúmenes numéricos requeridos, se someterían a la aprobación de la Comisión Municipal Permanente, o del Pleno en donde no existiera. Después se expondrían al público, junto con el resumen numérico, durante un plazo de quince días, y de treinta en los municipios que superasen los cien mil habitantes, para que los interesados pudieran presentar reclamaciones. Resueltas las reclamaciones por la alcaldía y notificadas en forma a los interesados, el padrón sería remitido a la Delegación provincial del INE $\left(\operatorname{art}^{\mathrm{o}} 100\right)^{49}$. Y con él, cada ayuntamiento enviaría un resumen numérico de todas las hojas de inscripción, totalizado por secciones y distritos, y el resumen general de la población por triplicado art $^{0}$ 101), clasificada la población en ambos según su sexo, y calificación (cabezas de familia, vecinos, domiciliados y transeúntes).

Examinada la documentación presentada, y una vez comprobado que se ajustaba a las normas del INE, se procedería a su aprobación o a la formulación de reparos, si era el caso. Estos reparos debían notificarse al ayuntamiento en un plazo no superior a tres meses $\left(\operatorname{art}^{\mathrm{o}} 102.2\right)$. La aprobación quedaría reflejada en una diligencia con la firma del delegado y el sello de la Delegación. A continuación se remitiría un ejemplar del resumen numérico general a la Dirección General de la Administración

\footnotetext{
${ }^{49}$ En el artículo 102.3 se establece que en los municipios de más de 10.000 habitantes, y en las capitales de provincia, los Delegados provinciales de Estadística podían no exigir el envío de las hojas de inscripción a sus delegaciones, pudiendo examinarlas por sí o por medio de sus funcionarios en las dependencias municipales".
} 


\section{MARIANO GARCÍA RUIPÉREZ \\ EL EMPADRONAMIENTO MUNICIPAL EN ESPAÑA}

Local, y se procedería a publicar las cifras resultantes de la población de hecho y de derecho en el Boletín Oficial de cada provincia ( $\operatorname{rrt}^{\mathrm{o}} 103$ ).

En esta importante norma se aclara que "el padrón municipal de habitantes renovado estará constituido por el conjunto de las hojas de inscripción padronal así ordenadas desde el momento de tal aprobación" ( $\operatorname{art}^{\circ}$ 100.4), refiriéndose a la efectuada por el Pleno o la Comisión Municipal Permanente. Los ayuntamientos estaban obligados a conservarlas encuadernadas y ordenadas ( $\operatorname{art}^{\circ} 104.3$ ). Con ellas confeccionarían un fichero, por orden alfabético de apellidos, conforme a una ficha modelo aprobada por el INE. Este fichero, que podría ser "mecanizado" era obligatorio en todos los municipios de más de 5.000 habitantes, y potestativo en los demás $\left(\operatorname{art}^{\mathrm{o}}\right.$ 104.1)

Cuando la renovación padronal coincidiera con la de elaboración de un Censo de Población las operaciones se harían simultáneamente, repartiéndose a la vez ambas hojas y con arreglo a un procedimiento establecido en el artículo 105.

Las rectificaciones anuales se realizarían reflejando las altas y bajas por movimiento natural de la población, por cambios de residencia, por cambios de domicilio y por alteraciones en la clasificación vecinal ( $\operatorname{art}^{0}$ 93.2). Para su cumplimiento los cabezas de familia, o si era el caso los tutores, herederos, parientes, etc., estaban obligados a comunicar a la alcaldía, en un plazo de ocho días, las alteraciones que deban producirse en las hojas de inscripción a consecuencia de nacimientos, matrimonios, defunciones, mayorías de edad y cambios de domicilio dentro del mismo término, para que el ayuntamiento realizara las correspondientes rectificaciones en las hojas de inscripción o en las adicionales que fueran necesarias ( $\left.\operatorname{art}^{\circ} 106\right)$, basándose en las declaraciones presentadas y en las comprobaciones realizadas ( $\left.\operatorname{art}^{\circ} 107\right)$. Es decir, los cambios se registraban en las hojas de inscripción elaboradas durante la renovación quinquenal o en otras hojas adicionales.

Todos los años se rectificaría el resumen numérico del padrón municipal en la fecha que se determinara teniendo en cuenta las alteraciones producidas. La rectificación expresaría numéricamente por cada hoja, vivienda, sección, distrito y núcleo de población esas alteraciones, con el resumen general de la población resultante, siguiendo un modelo aprobado por el INE ( $\operatorname{art}^{\mathrm{o}} 108$ ). Una vez confeccionada por el ayuntamiento se sometería a la aprobación de la Comisión Municipal Permanente, o del Pleno en donde ésta no existiera, siguiendo a continuación la misma tramitación que la observada durante la renovación quinquenal del padrón ( $\left.\operatorname{art}^{\circ} 109\right)$.

Al alcalde, o concejal en quien delegase, le competía la declaración de residencia o vecindad (cuando era realizada de oficio), la aprobación de la clasificación vecinal de cada habitante, la resolución de las solicitudes de declaración de residen- 


\section{MARIANO GARCÍA RUIPÉREZ \\ EL EMPADRONAMIENTO MUNICIPAL EN ESPAÑA}

cia y vecindad presentadas por los interesados, etc. Contra sus resoluciones, que debían quedar recogidas en el Libro de Resoluciones, se podían presentar reclamaciones en el plazo de quince días, tras la recepción de la notificación. Ése era el mismo periodo que tenía para resolverlas. Si no estaban de acuerdo, podían elevar recurso de alzada ante el gobernador civil, que tras ser informado por el Delegado provincial de Estadística, resolvía el recurso de manera definitiva ( $\left.\operatorname{art}^{\circ} 111\right)$.

En nuestro repaso legislativo la siguiente norma de interés es el Decreto número 409 de 6 de marzo de $1975^{50}$ del Ministerio de la Presidencia por el que se regula la formación del padrón municipal y se promueve su mecanización. Por él se autoriza a los ayuntamientos que tuvieran ya mecanizado el padrón a entregar las hojas de inscripción en la próxima renovación quinquenal ya rellenadas con los datos de las personas inscritas. Los cabezas de familia o quienes les sustituyeran podían ratificarlas, rectificarlas o completarlas ( $\operatorname{art}^{\mathrm{o}} 3$ ). Sería el INE el organismo encargado de coordinar la mecanización de los padrones dictando las normas que considerara precisas y realizando las tareas de asesoramiento técnico y control de las operaciones padronales.

Una Orden de 14 de mayo de $1975^{51}$ estableció las normas para la renovación del padrón municipal con referencia a las doce de la noche del día 31 de diciembre de 1975. En sus anexos se publicaron distintos modelos. El anexo $\mathrm{II}^{52}$ correspondía al modelo de hoja de inscripción padronal que debía usarse en esa renovación. En su anexo III se incluían las normas técnicas de mecanización a que habrían de adaptar sus programas los ayuntamientos que pretendieran mecanizar el padrón. En su disposición quinta se detenía en la renovación quinquenal del padrón con hojas de inscripción cuyos datos habían sido previamente anotados, salvo algunas casillas, que debían ser emitidas por ordenador con arreglo al modelo oficial. También se aclaraban los requisitos que debían cumplir los ayuntamientos que desearan implantar un sistema de comprobación permanente de la actualización de los datos padronales (disposición $6^{\mathrm{a}}$ ). Por último, en su disposición $9^{\mathrm{a}}$, se ordenaba la creación en los ayuntamientos de una Oficina de Empadronamiento, dependiente del INE, que sólo existiría durante el tiempo que durasen los trabajos padronales.

\footnotetext{
${ }^{50}$ Boletín Oficial del Estado de 13 de marzo de 1975.

${ }^{51}$ Boletín Oficial del Estado de 3 de junio de 1975.

${ }^{52} \mathrm{El}$ anexo I daba instrucciones a los ayuntamientos sobre los trabajos preliminares que debían realizar para la renovación del padrón. Los resultados se reflejaban en distintos formularios publicados con la mencionada Orden de 14 de mayo de 1975.
} 


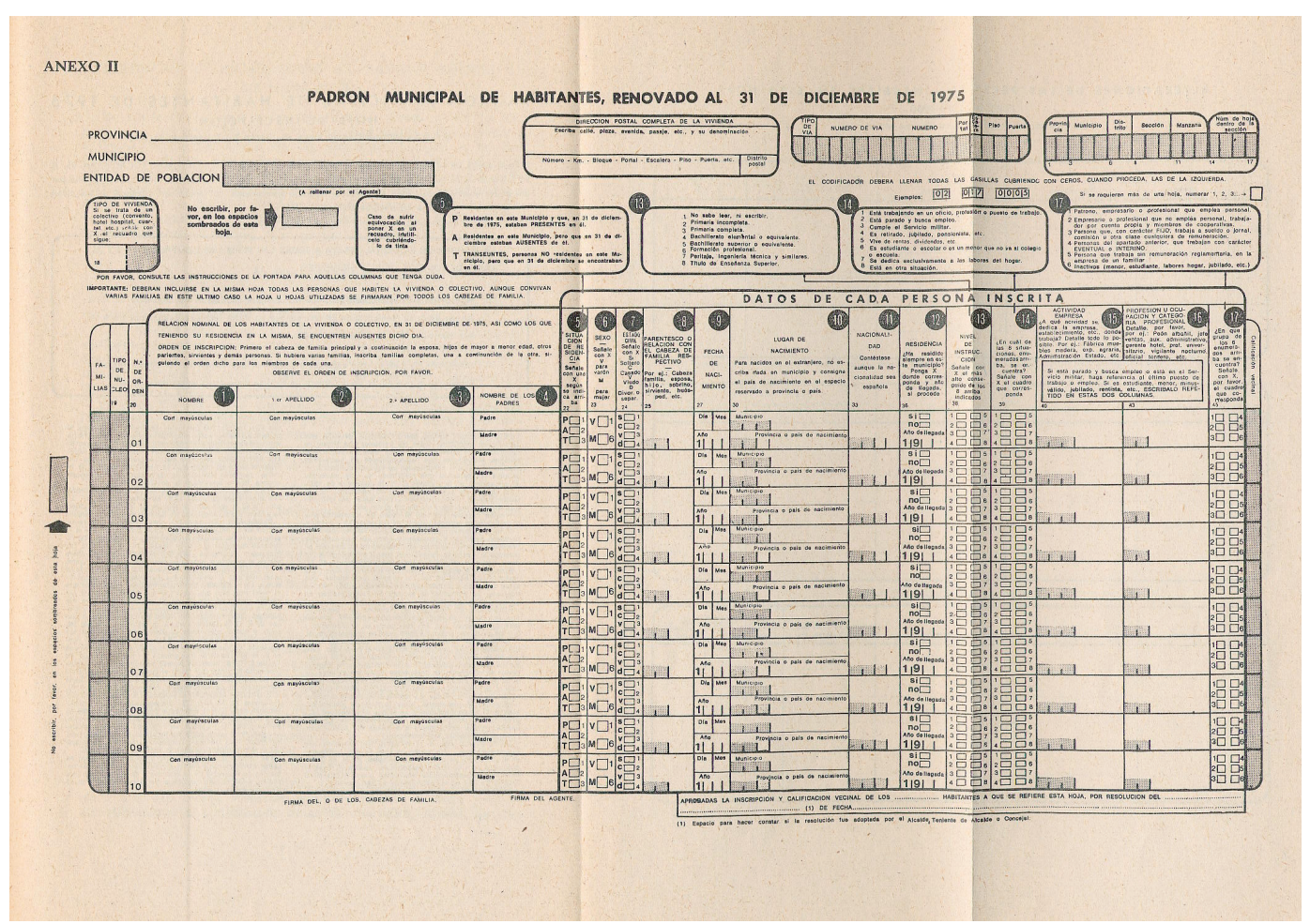

Figura 7. Modelo oficial de la hoja del padrón municipal de habitantes del año 1975.

En el anexo III de esta Orden se señala que el padrón de habitantes "estará constituido bien por la relación continuada de habitantes del término, con expresión de sus respectivas calidades", con arreglo al contenido del artículo 89 del Decreto de 14 de enero de 1971, "o por el conjunto de las hojas de inscripción padronal ordenadas, numeradas, encuadernadas por secciones y diligenciadas" tal y como recogía el artículo 100 de ese mismo Decreto. Sin duda, muy pocos ayuntamientos elaborarían con las hojas esa relación, quedando este término como un elemento de la definición del padrón y no como un tipo documental diferente.

La resolución aprobatoria que debía firmar el alcalde, o concejal en quien delegase, en cada una de las hojas de inscripción (artículos 100 y 110 del Decreto $65 / 1971$ ) podía realizarse de forma individual o bien en el conjunto de las hojas de una calle o sección.

Con esta Orden de 14 de mayo de 1975 se publicaron los modelos de certificaciones, de resúmenes numéricos, de declaraciones duplicadas de baja de residencia, de declaraciones de cambio de domicilio, de relación de altas provisionales mensua- 


\section{MARIANO GARCÍA RUIPÉREZ \\ EL EMPADRONAMIENTO MUNICIPAL EN ESPAÑA}

les, etc. ${ }^{53}$ Incluso, como anexo 9 del anexo III relativo a "Directrices técnicas", se establece el diseño de fichero, código y soporte para la mecanización del padrón ${ }^{54}$.

La Ley de Bases del Estatuto de Régimen Local de 19 de noviembre de 1975 dedica su base $2^{\mathrm{a}}$ a la "Población Municipal" incluyendo únicamente la distinción entre residentes (vecinos, fueran cabeza de familia o no, y domiciliados) y transeúntes, y la existencia del padrón municipal en todas las localidades.

Más importancia tendría la Ley 7/1985, Reguladora de las Bases del Régimen Local, de 2 de abril de ese año ${ }^{55}$ con la que se establece el marco jurídico de los ayuntamientos democráticos, y que aún está vigente. El capítulo $1^{\circ}$ de su Título II se detiene en "Territorios y población" (artículos 12-18). En su artículo 15 se recuerda la obligación de estar empadronados a todos los españoles o extranjeros que vivieran en España. Para poder tener el alta en el padrón de un municipio era preciso presentar el certificado de baja en el padrón del municipio en el que se residiera con anterioridad ( $\left.\operatorname{art}^{\circ} 15.1\right)$. Aunque para inscribirse en el padrón como transeúnte no era preciso este requisito ( $\left.\operatorname{art}^{\mathrm{o}} 15.2\right)$.

La condición de residente se adquiría en el momento de realizar la inscripción en el padrón. No había que esperar a que transcurriera ningún plazo. Además los residentes sólo se clasificaban en vecinos y domiciliados ( $\left.\operatorname{art}^{0} 16\right)$, sin que se recogiera la distinción en cabezas de familia.

En esta norma se define el padrón municipal como la relación de los residentes y transeúntes de un término municipal ( $\operatorname{rrt}^{\mathrm{o}} 17$ ), si bien no se especifica la información en él contenida al establecer que en él figurarían de todos los residentes "los datos personales precisos para las relaciones jurídicas públicas...”. La formación, mantenimiento y rectificación del padrón corresponde a los ayuntamientos que procederían a su renovación quinquenal y a su rectificación anual ( $\left.\operatorname{art}^{\mathrm{0}} 17.2\right)$. También debían elaborar un padrón especial de españoles residentes en el extranjero art $^{\mathrm{o}}$ 17.3).

En el desarrollo de su articulado y en sustitución del Reglamento de 1952 fue aprobado el Real Decreto 1690/1986, de 11 de julio, de Población y Demarcación Territorial de las Entidades Locales ${ }^{56}$, que dedica su Título II a "De la población y del Padrón Municipal" (Arts. 53-87).

\footnotetext{
${ }^{53}$ Todos estos modelos fueron publicados también en el libro intitulado El Padrón de Habitantes: Normas para su renovación y mecanización, Madrid, 1975.

${ }^{54}$ En concreto en cuanto a soporte recomendado se refiere a la "cinta magnética" con una densidad de grabación de 800 b. p. i., de 9 pistas, y un código de grabación EBCDIC. También se señala en este anexo el tipo de papel que debía utilizarse en los distintos formularios.

${ }^{55}$ Boletín Oficial del Estado de 3 de abril de 1985.

${ }^{56}$ Boletín Oficial del Estado de 14 de agosto de 1986.
} 


\section{MARIANO GARCÍA RUIPÉREZ \\ EL EMPADRONAMIENTO MUNICIPAL EN ESPAÑA}

Comienza este texto distinguiendo entre población de derecho y de hecho, y entre residentes, fueran vecinos o domiciliados, y transeúntes ( $\operatorname{art}^{\mathrm{o}} 53$ ). Estos últimos podían solicitar su inclusión como tales en el padrón municipal de habitantes, al margen de la fecha de renovación padronal, siempre que tuvieran una permanencia prolongada en el municipio y sin presentar el certificado de baja de la localidad en donde tuvieran fijada su residencia ( $\left.\operatorname{art}^{\circ} 55\right)$. También comunicarían al Ayuntamiento su marcha definitiva, cuando ésta se produjera, para que se procediera a darles de baja en el padrón como transeúntes.

Toda persona que tuviera fijada su residencia en una localidad española y decidiera trasladarse a vivir a otra debía solicitar a su Ayuntamiento la baja en el padrón como tal residente, en un impreso normalizado en donde figuraría el municipio de destino. Recibida la "solicitud", el Ayuntamiento acordaría la baja en el padrón y expediría el certificado expresivo de dicha baja a favor del interesado. A continuación, y durante un plazo de treinta días, contados desde la fecha de la resolución de la baja, debía presentar una solicitud de alta en el padrón en el municipio de destino, acompañada de la certificación de baja de la localidad de origen. La solicitud de residencia sería resuelta por el Alcalde y notificada al interesado ( $\left.\operatorname{art}^{\circ} 56\right)$. Si el residente español procedía del extranjero era preciso un documento consular ( $\operatorname{art}^{\mathrm{o}} 57$ ).

El padrón municipal es definido en su artículo 62. Los datos en él contenidos se acreditarían por medio de certificaciones expedidas por el Secretario del Ayuntamiento ( $\operatorname{art}^{\circ}$ 62.2). Esos datos se recogen en el artículo 65. Así de los residentes y, en su caso, de los transeúntes, debía constar: a) Los nombres y apellidos; b) Sexo; c) Estado civil; d) Profesión u ocupación; e) Nacionalidad; f) Lugar y fecha de nacimiento; g) Número de documento nacional de identidad o, tratándose de extranjeros, el documento que lo sustituya ${ }^{57}$; h) Domicilio; i) Certificado o título escolar, académico o profesional que se posea; j) Parentesco o relación con la persona principal de la familia...; k) Tiempo de residencia en el municipio; 1) Cuantos otros datos se exijan...

Tanto en la renovación como en su rectificación, los ayuntamientos seguirían las instrucciones y directrices aprobadas por el Instituto Nacional de Estadística y la Dirección General de Administración Local ( $\operatorname{art}^{\circ}$ 67). La renovación quinquenal en los años terminados en 1 coincidiría con la establecida para los censos de población y vivienda. Y en los años terminados en 6 sería establecida por Real Decreto en una fecha comprendida entre el 1 de marzo y el 31 de mayo $\left(\operatorname{art}^{\circ} 66.2\right)$. 


\section{MARIANO GARCÍA RUIPÉREZ \\ EL EMPADRONAMIENTO MUNICIPAL EN ESPAÑA}

El padrón municipal renovado estaría constituido por la relación de residentes presentes y ausentes deducidos de las hojas de inscripción, y por los transeúntes que hubieran solicitado su inscripción como tales. Esta relación podría tener soporte informático $\left(\operatorname{art}^{\mathrm{o}} 74.3\right)$.

La obligación de empadronarse correspondía a todos los que residieran en un municipio en la fecha de renovación del padrón, y a los que, en cualquier tiempo, cambiaran de residencia ( $\left.\operatorname{art}^{\circ} 64\right)$. En la renovación se utilizarían las tradicionales "hojas de inscripción" ( $\operatorname{art}^{\circ} 68.1$ ), repartidas a domicilio para que fueran cumplimentadas por la persona principal de la familia, o quien le sustituyera, incluyendo su firma con nombre y apellidos ( $\left.\operatorname{art}^{\circ} 70.1\right)$. Los ayuntamientos podían verificar la exactitud de los datos, exigiendo para ello la presentación de los documentos precisos ( $\left.\operatorname{art}^{\mathrm{o}} 70.4\right)$, o requiriendo para personas determinadas la colaboración del Registro Civil $\left(\operatorname{art}^{\mathrm{o}} 71\right)$.

Los residentes inscritos durante la renovación padronal podían clasificarse en residentes presentes y en residentes ausentes ( $\operatorname{art}^{\circ} 72$ ). Las personas que se encontraran accidentalmente en un municipio, que no fuera el de su residencia habitual, debían rellenar también las hojas de inscripción siendo clasificados como transeúntes $\left(\operatorname{art}^{0} 70.2\right)$.

Las hojas de inscripción, una vez corregidas, comprobadas y diligenciadas, serían ordenadas y numeradas correlativamente por distritos, secciones, manzanas, calles, edificios y viviendas ( $\left.\operatorname{art}^{\circ} 74\right)$. Con ellas se elaborarían los resúmenes numéricos provisionales de habitantes que serían sometidos a aprobación al Pleno municipal ( $\left.\operatorname{art}^{\mathrm{o}} 74.2\right)$.

Tras esa aprobación, y durante un mes, el padrón estaría expuesto al público para que los interesados presenten reclamaciones contra su inclusión, exclusión o corrección de datos. Durante ese tiempo serían informados sobre su inscripción, pudiendo consultar la hoja por ellos cumplimentada ( $\left.\operatorname{art}^{\mathrm{o}} 74.4\right)$. Resueltas las reclamaciones por los respectivos alcaldes, y notificadas a los interesados, podían éstos interponer recurso de reposición ante esa máxima autoridad local. Los alcaldes resolverían esos recursos previo informe del órgano de la Administración del Estado competente en materia de Estadística ( $\left.\operatorname{art}^{\mathrm{0}} 74.5\right)$.

Los ayuntamientos debían remitir al INE, en la forma y plazo que éste determinara, el resumen numérico definitivo de la población total del municipio clasificada por sexo y situación de residencia (presentes, ausentes y transeúntes), y cuando

${ }^{57}$ En la disposición adicional de este Reglamento se establece que el número del Documento Nacional de Identidad no se incluiría en las hojas de inscripción hasta que no se aprobara una norma 


\section{MARIANO GARCÍA RUIPÉREZ \\ EL EMPADRONAMIENTO MUNICIPAL EN ESPAÑA}

proceda, por distritos y secciones ( $\operatorname{art}^{\mathrm{o}} 75$ ). También se distinguiría la población de hecho y de derecho. Examinados esos resúmenes, el INE daría su conformidad o comunicaría los reparos que estime oportunos ( $\operatorname{art}^{\circ} 76$ ).

Los ayuntamientos, con las hojas de inscripción padronal, elaborarían dos ficheros de las personas residentes en su término municipal. Uno estaría ordenado por distritos, secciones y domicilios, y el otro por orden alfabético de apellidos ( $\operatorname{art}^{\mathrm{o}}$ 77.1). Si se optaba por mecanizar estos ficheros, sus contenidos y formatos debían cumplir con las condiciones mínimas exigidas por el INE ( $\operatorname{rrt}^{\mathrm{0}} 77.3$ ).

Las rectificaciones anuales se llevarían a cabo reflejando las altas y bajas por movimiento natural de la población, los cambios de residencia y los cambios de domicilio ( $\left.\operatorname{art}^{\circ} 68.2\right)$.

Los cambios de domicilio dentro de un mismo término municipal debían ser comunicados a los ayuntamientos por los interesados en un plazo no superior a ocho días desde que éstos se produjeran ( $\left.\operatorname{art}^{0} 79.1\right)$. El movimiento natural de la población dentro de una localidad (altas y bajas por nacimientos y defunciones) sería registrado en el padrón "con la documentación que los Ayuntamientos reciban del expresado Registro Civil", o en su caso del INE. Con esas "declaraciones" y "comprobaciones" se procedería a actualizar el padrón municipal de habitantes ( $\left.\operatorname{art}^{\circ} 80\right)$.

Todos los años, a fecha de 1 de enero, sería rectificado el resumen numérico del padrón municipal de habitantes. La rectificación expresaría numéricamente las distintas alteraciones producidas y el resumen general de la población resultante con arreglo a los impresos que estableciera el INE ( $\left.\operatorname{art}^{\circ} 81\right)$.

Su procedimiento de aprobación era parecido al seguido con el padrón. Una vez aprobada la rectificación por el Pleno municipal estaría expuesta al público durante quince días a efecto de que los interesados presentaran sus reclamaciones, que posteriormente debían ser resueltas por el Ayuntamiento. Después se enviaría el resumen numérico definitivo de la rectificación anual al INE en la forma y plazos que éste determinara ( $\operatorname{art}^{\circ} 82.1$ ), para que procediera a su comprobación, corrigiendo los errores que advirtiere ( $\left.\operatorname{art}^{\circ} 84\right)$. Los datos relativos al número de habitantes debían ser comunicados también al Registro de Entidades Locales en el mes siguiente al de la aprobación de la rectificación. Asimismo en febrero debían comunicar a la Delegación Provincial de la Oficina del Censo Electoral los datos exigidos por la normativa electoral ( $\left.\operatorname{art}^{\circ} 85\right)$.

La existencia de un padrón especial de españoles residentes en el extranjero que debían formar los ayuntamientos está contemplada en el artículo 86.

expresa que así lo determinara. 


\section{MARIANO GARCÍA RUIPÉREZ \\ EL EMPADRONAMIENTO MUNICIPAL EN ESPAÑA}

Los alcaldes podían declarar de oficio la residencia de los españoles y extranjeros que habitando más de dos años en el término municipal no figuraran inscritos en el padrón. Esas resoluciones serían notificadas a los interesados y comunicadas a los ayuntamientos en donde anteriormente figuraran inscritos ( $\operatorname{art}^{\circ} 83$ ). También correspondía a los alcaldes sancionar con multas el incumplimiento de las obligaciones contempladas en esta disposición, especialmente la negativa a cumplimentar las hojas de inscripción o hacerlo incluyendo errores o falsedades ( $\operatorname{art}^{\circ} 87$ ).

Como hemos podido comprobar en este Reglamento no se establece la posibilidad de que previamente los ayuntamientos cumplimentaran, durante la renovación quinquenal y antes de su entrega a los interesados, parte de las casillas de las hojas de inscripción merced a sus registros mecanizados ${ }^{58}$.

Por la Ley 4/1996 ${ }^{59}$, que modifica el contenido de la Ley 7/1985 en relación con el padrón municipal de habitantes, nace el padrón continuo y permanentemente actualizado. Con esta ley desaparecen las renovaciones quinquenales. Y se elimina la distinción entre vecino y domiciliado y la inclusión de los transeúntes. Por ella ya no se recogen como datos obligatorios en la inscripción padronal ni el estado civil, ni la profesión u ocupación, ni el tiempo de residencia en el municipio, ni el parentesco con el cabeza de familia (art. 16.2). Pero se mantiene la previsión de que sea la normativa estatal la que establezca los criterios mediante los cuales los ayuntamientos lleven a cabo la formación, mantenimiento, revisión y custodia de los padrones municipales. Aunque lo más importante de este norma desde el punto de vista archivístico es que indica que la gestión del padrón municipal se realizará a partir de entonces por medios informáticos (art. 17.1). Por su disposición transitoria única se determina que en el año 1996 se procedería a la última renovación padronal quinquenal en toda España. Y ésta es la situación actual.

Gracias a las disposiciones reseñadas todos los ayuntamientos españoles pueden conservar los padrones municipales de habitantes elaborados anualmente entre 1823 y 1869 o cada cinco años, entre 1870 y 1996. En este último periodo deben existir, también, rectificaciones anuales (altas, bajas y cambios de domicilio) y resúmenes numéricos. Todos estos documentos constituyen la principal fuente para el estudio demográfico de la población española, y por ende del movimiento natural y de las corrientes migratorias. La calidad y cantidad de la información ofrecida no

\footnotetext{
${ }^{58}$ La normativa aprobada en el desarrollo de este Reglamento se iniciaría posiblemente con la Resolución de 30 de diciembre de 1986 por la que se dictan instrucciones técnicas a los ayuntamientos sobre gestión del padrón y su rectificación (BOE de 24 de enero de 1987) y llegaría hasta la actualidad.

${ }^{59}$ BOE de 12 de enero de 1996.
} 


\author{
MARIANO GARCÍA RUIPÉREZ \\ EL EMPADRONAMIENTO MUNICIPAL EN ESPAÑA
}

tiene parangón con la producida con anterioridad al año 1824. Los distintos campos en los que están estructuradas las hojas de declaración familiar (nombre y apellidos, edad, fecha de nacimiento, domicilio, estudios realizados, relación de parentesco, fecha de alta en el padrón) ofrecen muchas posibilidades para los investigadores preocupados por la historia social, la demográfica, la genealógica, etc. ${ }^{60}$

\footnotetext{
${ }^{60}$ La utilización de los padrones para la realización de estudios demográficos por los historiadores es muy habitual. Estos documentos han llamado también la atención de los administrativistas especializados en derecho local, pero existen muy pocas aportaciones desde el campo de la Archivística. Ahora solo destacamos el artículo ya citado de $\mathrm{M}^{\mathrm{a}}$ Sandra García Pérez, y las paginas, dedicadas a los padrones por el Grupo de Madrid en su Manual de Tipología Documental de los Municipios, (Madrid, 1988, en concreto las pp. 54-56). Aunque en este último trabajo sólo se estudie esta serie entre 1952 y 1986. Para la primera mitad del siglo XIX es muy útil el libro de M. VAQUERIZO GIL y A. RODRÍGUEZ FERNÁNDEZ, Archivo Histórico Provincial de Cantabria: Índice de Padrones y Vecindario, Santander, 1998.
} 